Note: This is a post-print peer-reviewed draft of the journal article:

S. M. García-Rodríguez, J. Costa, K. E. Rankin, R. P. Boardman, V. Singery, J. A. Mayugo (2020) "Interleaving light veils to minimise the trade-off between mode-I interlaminar fracture toughness and in-plane properties". Composites Part A: Applied Science and Manufacturing Vol. 128, 105659

DOI: 10.1016/j.compositesa.2019.105659

Accepted: $11 / 10 / 19$

The final published version is available from the publisher online via:

https://www.sciencedirect.com/science/article/pii/S1359835X19304087?via\%3Dihub

https://doi.org/10.1016/i.compositesa.2019.105659 


\title{
Interleaving light veils to minimise the trade-off between mode-I interlaminar fracture toughness and in-plane properties
}

\author{
S.M. García-Rodríguez ${ }^{\mathrm{a}}$, J. Costa ${ }^{\mathrm{a}, *}$, K.E. Rankin ${ }^{\mathrm{b}}$, R.P. Boardman ${ }^{\mathrm{b}}$, V. Singery $^{\mathrm{c}}$, \\ J.A. Mayugo ${ }^{a}$ \\ ${ }^{a}$ AMADE, Polytechnic School, University of Girona, Av. Universitat de Girona, 4. 17003 Girona, \\ Spain \\ ${ }^{b}$ Faculty of Engineering and Physical Sciences, University of Southampton, Southampton SO17 1BJ, \\ United Kingdom \\ ${ }^{c}$ Chomarat, 39 Avenue de Chabannes, 07160, Le Cheylard, France
}

\begin{abstract}
Interleaving heavy micro-fibre veils, commonly used to improve interlaminar fracture toughness, severely compromises tensile and compressive properties. To reduce the trade-off, this study interleaved two different types of light $\left(4 \mathrm{~g} / \mathrm{m}^{2}\right)$ co-polyamide veils into a thin-ply quasi-isotropic baseline laminate. Sub-micron resolution X-ray micro-computed tomography provided insight into the after-manufacturing state of the veil fibres as well as into the fracture process zone of mode-I interlaminar fracture toughness specimens. The veil fibre diameter was the key parameter in determining the tensile properties (the veil with thinner fibres avoided resin accumulation at the interfaces and left the baseline properties unaffected). Both veils decreased the compressive strength by up to $9 \%$. Mode-I crack propagation was controlled by the adhesion between the veil fibres and resin. Veils fibres with the higher adhesion deflected crack propagation to the surrounding $0^{\circ}$ plies, which improved mode-I initiation and propagation interlaminar fracture toughness (by 101\% and 43\%).

Keywords: Thin-plies; Non-woven veils; B. Mechanical properties; D. CT analysis.
\end{abstract}

\footnotetext{
${ }^{*}$ Corresponding author

Email address: josep.costa@udg.edu (J. Costa)
} 


\section{Introduction}

In an effort to reduce costs, the airline industry is increasingly considering thinner composite laminates manufactured using out-of-autoclave methods such as resin transfer moulding (RTM). However, infusion techniques demand low-viscosity inherently brittle resins, which lowers the component's damage tolerance [1]. This is even more accentuated when laminates are made of "thin-plies" (i.e. plies thinner than $125 \mu \mathrm{m}[2])$. Thin-ply laminates are a new generation of composite materials that, despite increasing certain mechanical properties [2-15], entail brittle damage mechanisms compared to their conventional-ply counterparts. [6, 16-20].

From an industrial point of view, brittleness can be reduced with toughening methods that are cheap and easy to incorporate during manufacturing. Nash et al. [1] wrote a comprehensive review on toughening methods that use a thermoplastic modifier. They classified them into two groups: bulk resin modification and interlaminar toughening. The first group increases the fracture toughness of the resin by dispersing/dissolving external agents, which normally increases the viscosity. The second group incorporates a toughening system such as thermoplastic particles or thin films in the interfaces. However, the particles migrate during resin infusion while the films inhibit through-thickness resin flow. To overcome these difficulties, this study used micro-fibre "non-woven veils" i.e., thin heterogeneous networks made of dispersed micro-fibres [1, 21-23]. The main advantages are that non-woven veils are commercially available, relatively cheap, can be manually placed during the lay-up and allow resin infusion through the z-direction (the veils are permeable) [1].

Interleaving polyamide (PA) veils improves the mode-I interlaminar fracture toughness $\left(G_{\mathrm{IC}}\right)$ of the non-interleaved laminate [1, 24-32]. Kuwata [33] explained that a critical parameter for $G_{\mathrm{IC}}$ performance is the adhesion between veil fibres and matrix. Veil fibres with a low adhesion pull out from the matrix and dissipate part of the fracture energy by fibre bridging (as observed in $[1,22,24-32,34]$ ). Veil fibres with a higher adhesion deflect crack propagation away from the veil, which may leave 
the baseline $G_{\mathrm{IC}}$ unaffected [29]. Finally, some authors report a mixture of interlaminar and interfacial crack growth [27, 30-32, 35].

The $G_{\mathrm{IC}}$ of a given interleaved system improves by increasing veil fibre areal weight (i.e. weight per unit area of veil) [23, 26, 32, 35]. For example, Beylergil et al. [32] reported a $G_{\mathrm{IC}}$ improvement of $231 \%$ and $737 \%$ by interleaving 17 or $50 \mathrm{~g} / \mathrm{m}^{2}$ polyamide veils. However, in materials science, every enhancement has an associated cost, in particular toughness and strength are mutually exclusive [36]. Beylergil et al. [32] characterised the tensile and compressive properties of a carbon/epoxy $\left[0^{\circ}\right]_{4}$ laminate interleaved with the 17 or $50 \mathrm{~g} / \mathrm{m}^{2}$ PA veils in every interface. Both the tensile and compressive moduli decreased with improved veil fibre areal weight ( $\mathrm{E}_{11}$ by up to $34 \%, \mathrm{E}_{22}$ by up to $23.70 \%, \mathrm{G}_{12}$ by up to $21 \%$ and the compressive modulus by up to 13\%), and likewise the tensile and compressive strength (by up to $41 \%$ and $13 \%)$. The authors attributed the reduction of tensile properties to the increase in laminate thickness brought about by the veils (both veils increased nominal thickness by up to $38 \%$ ), which also agrees with the tendencies reported elsewhere [24, 34, 37].

Based on the observations, a practical balance between laminate thickness, mode-I interlaminar fracture toughness and in-plane mechanical properties should rely on veils with relatively low fibre areal weight. This study interleaved two types of light co-polyamide veils into a thin-ply quasi-isotropic baseline laminate. Both veils had a fibre areal weight of $4 \mathrm{~g} / \mathrm{m}^{2}$ which, according to the author's knowledge, is the lightest reported for interlaminar fracture toughness testing (values range from 7 to $50 \mathrm{~g} / \mathrm{m}^{2}$ $[1,22-32,34,35,37])$. Sub-micron resolution X-ray tomography $(\mu \mathrm{CT})$ provided comprehensive insight into the after-manufacturing state of the veil fibres as well as into the fracture process zone of the double cantilever beam (DCB) specimens. One of the interleaved configurations enhanced the baseline $G_{\mathrm{IC}}$ with no associated reduction of the tensile properties. Besides this, a previous study demonstrated a compression after impact (CAI) strength improvement of up to $28 \%$ for impact at $14 \mathrm{~J}$ [38]. 


\section{Materials and Methods}

\subsection{Materials}

The materials used in this experimental program were the $\left(0^{\circ} / 45^{\circ}\right)$ and $\left(0^{\circ} /-45^{\circ}\right)$ warp-knitted non-crimp fabrics (NCFs) made of T700 GC carbon and 35 dtex polyester yarns, commercialized by Chomarat under the brand name C-PLYTM . The fibre areal weight of the NCFs was $134 \mathrm{~g} / \mathrm{m}^{2}$, corresponding to $67 \mathrm{~g} / \mathrm{m}^{2}$ per unidirectional ply. NCFs reduce labour costs because they lay several layers at the same time, which is ideal for handling thin-plies [39].

Two types of CoPA non-woven veils were investigated: $\mathrm{V}_{1}$ and $\mathrm{V}_{2}$. Both veils had a similar fibre areal weight $\left(4 \mathrm{~g} / \mathrm{m}^{2}\right)$ but different veil fibre melting temperature and veil fibre diameter. The melting point of $\mathrm{V}_{2}$ was higher than the curing temperature and slightly lower than the laminate's post-curing temperature (the curing and post-curing temperatures were $170{ }^{\circ} \mathrm{C}$ and $180^{\circ} \mathrm{C}$, respectively). In contrast, the melting point of $\mathrm{V}_{1}$ was significantly higher than $180{ }^{\circ} \mathrm{C}$. The fibre diameter of $\mathrm{V}_{1}$ and $\mathrm{V}_{2}$ was $37 \pm 4$ $\mu \mathrm{m}$ and $11 \pm 2 \mu \mathrm{m}$, respectively, where \pm means standard deviation (at least 50 fibres were measured using an optical microscope). For a given veil fibre areal weight, the veil fibre diameter is the parameter that intuitively controls the surface area covered by veil fibres (the thinner the fibres, the more closely packed the network and the higher the surface area covered by veil fibres is [23]). This tendency was verified using an optical microscope. First, different regions of $\mathrm{V}_{i}(i=1,2)$ were inspected under similar magnification (at least 15 areas of $1 \mathrm{~cm}^{2}$ were observed per veil). Then, the fibres were segmented from the background using Image J [40]. Finally, the percentage area covered by $\mathrm{V}_{1}$ and $\mathrm{V}_{2}$ fibres was calculated: $22 \pm 2 \%$ and $65 \pm 5 \%$. No further details of the veils can be disclosed due to confidentiality.

Laminates were manufactured by resin transfer moulding using HexFlowß RTM6 epoxy resin. The infusion temperature and pressure were $120^{\circ} \mathrm{C}$ and a maximum of 8 bars, respectively. After infusion, the laminates were cured at $170{ }^{\circ} \mathrm{C}$ for $90 \mathrm{~min}$ and, once cooled, post-cured at $180{ }^{\circ} \mathrm{C}$ for $120 \mathrm{~min}$. (For further details of the 
manufacturing process refer to [38]). Two types of quasi-isotropic baseline laminate were designed. For in-plane testing, a $\left[\left(45^{\circ} / 0^{\circ}\right) /\left(-45^{\circ} / 90^{\circ}\right)\right]_{4 s}$ laminate approximately $2.2 \mathrm{~mm}$ thick. For mode-I fracture toughness testing, a $\left[\left(45^{\circ} / 90^{\circ}\right) /\left(-45^{\circ} / 0^{\circ}\right)\right]_{6 \mathrm{~s}}$ laminate of approximately $3.7 \mathrm{~mm}$ thickness. The former is the stacking sequence used for the CAI study [38] (which is also compatible with standards for tension and compression testing $[41,42])$. The latter is in agreement with interlaminar fracture

toughness standards $[43,44]$. Both configurations were interleaved with a different number of veils. For mode-I testing, a single veil was placed at the centre of the stack. For in-plane testing, a single veil was incorporated into every interface. Table 1 defines the notation and stacking sequence of the laminates. The fibre volume fractions of LTHIN ${ }_{I P}, L V 1_{I P}$ and $L V 2_{\text {IP }}$ in-plane laminates were $53.50 \pm 1.60 \%$, $53.50 \pm 1.70 \%$ and $53.70 \pm 1.30 \%$, respectively (five samples were measured per laminate following the standard EN 2564:1998 [45]). The average thicknesses of tested specimens were $2.30 \pm 0.20,2.20$ and 2.20 (the standard deviations of $\mathrm{LV} 1_{\mathrm{IP}}$ and $\mathrm{LV} 2_{\mathrm{IP}}$ were negligible and therefore were not reported). The fibre volume fractions of $\operatorname{LTHIN}_{G_{\mathrm{IC}}}, \mathrm{LV} 1_{G_{\mathrm{IC}}}$ and LV $2_{G_{\mathrm{IC}}}$ mode-I laminates were 50.30 $\pm 1.90,49.70 \pm 1.60$ and $53.30 \pm 0.20$, respectively (three samples were measured per laminate following the standard EN 2564:1998 [45]), where the higher fibre volume fraction of $L V 2_{G_{\mathrm{IC}}}$ resulted in the lowest laminate thickness (the average thicknesses of tested specimens were $3.80 \pm 0.20,3.90$ and $3.50 \pm 0.20 \mathrm{~mm}$ ). Finally, based on the density values calculated using the Archimede's principle [45], the increase of weight brought about by $\mathrm{V}_{i}$ veils $(i=1,2)$ was in all the cases lower than $0.5 \%$.

\subsection{Experimental tests}

Compression tests were performed using an electromechanical MTS INSIGHT囚100 testing machine (MTS systems corporation, USA) with a $100 \mathrm{kN}$ load cell. $12.70 \mathrm{x}$ $140 \mathrm{~mm}$ (width and length) specimens were tested using a compression fixture in accordance with the ASTM D6641/D6641M-14 standard [41]. The cross-head displacement rate was $1.3 \mathrm{~mm} / \mathrm{min}$. The compression strength was calculated by 
dividing the maximum load to failure by the specimen's cross-sectional area measured at the gage region. A minimum of 6 specimens were tested per material system.

Tensile tests were carried out using a servo-hydraulic MTS INSIGHTß250 testing machine (MTS systems corporation, USA) with a $250 \mathrm{kN}$ load cell. 25 x $210 \mathrm{~mm}$ (width and length) specimens were tested in accordance with the ASTM D3039/D3039M-14 standard [42]. 50 mm long glass fibre/epoxy tabs were bonded to the coupon ends. The cross-head displacement rate was $2 \mathrm{~mm} / \mathrm{min}$. To monitor for undesirable bending (in all the experiments less than 3\%), two strain gauges were affixed on opposite faces of each specimen. The tensile strength was calculated by dividing the maximum load to failure by the specimen's cross-sectional area measured at the gage region. The elastic modulus was estimated from the slope of a linear regression in the elastic regime of the stress strain curve (in the range of $0.10-0.30 \%$ strain), where the strain was calculated as the average reading of the two strain gauges. A minimum of 8 specimens were tested per material system.

Mode-I interlaminar fracture toughness experiments were performed using an electromechanical MTS INSIGHT®5 testing machine (MTS systems corporation, USA), a $5 \mathrm{kN}$ load cell and the side clamped beam hinge system designed by Renart et al. (2011) [46]. The width and length of the DCB specimens were 25 and $250 \mathrm{~mm}$. The length and thickness of the teflon insert were approximately $70 \mathrm{~mm}$ and $15 \mu \mathrm{m}$. Specimens were pre-cracked and subsequently loaded following the methodology described in the ASTM D5528/D5528-13 and ISO 15024 standards [43, 47]. The only deviation from the standards was the use of the side clamped beam hinges instead of loading blocks (the hinges are suggested by AITM1-0005 Airbus Internal Test Method [48]). The loading and unloading rates were 5 and $25 \mathrm{~mm} / \mathrm{min}$. Crack propagation was recorded using an optical system consisting of a high-resolution video camera (EOS REBEL t2I/EOS 550D, Canon Inc, Japan) and a long distance microscope (Questar QM 100 MK III, Questar Corporation, USA). Data were reduced using the modified compliance calibration method $[43,47]$. Mode-I initiation interlaminar fracture toughness $\left(G_{\text {Iinit }}\right)$ was computed using the force and displacement measured 
at the 5\%/max point after pre-cracking $[43,47]$. Mode-I propagation interlaminar fracture toughness $\left(G_{\text {Iprop }}\right)$ was the average toughness of the propagation increments between 20 and $40 \mathrm{~mm}$ (where the R-curves were consistently flatter in all of the batches, Fig. 6).

The entire testing matrix was performed at $23 \pm 2{ }^{\circ} \mathrm{C}$ and $50 \pm 5 \%$ humidity in the mechanical testing laboratory at the University of Girona. The laboratory holds ISO17025 and NADCAP (Non-Metallic Materials) accreditations.

\subsection{X-ray tomography inspection}

To gain understanding into the after-manufacturing state of veil fibres (including the potential debonding between veil fibres and the surrounding resin), LTHIN $_{\text {IP, }}$ $\mathrm{LV} 1_{\mathrm{IP}}$ and $\mathrm{LV} 2_{\mathrm{IP}}$ were inspected using sub-micron resolution $\mu \mathrm{CT}\left(\mathrm{LV} 1_{\mathrm{IP}}\right.$ and $\mathrm{LV} 2_{\mathrm{IP}}$ incorporate one veil into every interface). Inspections were performed with the Zeiss $160 \mathrm{kVp}$ Versa 510 scanner at the $\mu$-VIS X-ray Imaging Centre, Faculty of Engineering and Physical Sciences, University of Southampton (the equipment has a 2000 x 2000 pixels detector). The scan set-up was altered to use a 20X magnifying lens. Prior to inspection, 1 x $1 \mathrm{~mm}$ (width and thickness) rectangular parallelepipeds were cut/polished from pristine laminates (high-resolution tomography requires inspecting small volumes and yet, ideally, the object should rotate fully within the field of view FOV [49]). The scanning parameters were $60 \mathrm{kV}, 83.30 \mu \mathrm{A}, 5 \mathrm{~W}, 7 \mathrm{~s}$ exposure time, 4001 projections and $783 \mathrm{~nm}$ pixel size, corresponding to an FOV of approximately $800 \mathrm{~nm}$ (to reduce noise and inspection time, the detector was used in the $2 \times 2$ binning mode). The source to detector and source to object distances were 16.85 and $9.92 \mathrm{~mm}$, respectively, and the specimens were rotated through $360^{\circ}$ during the acquisition of the 4001 projection images. It is worth noting that the incident energy was relatively low $(60 \mathrm{kVp})$ in order to enhance the contrast between the CoPA veil fibres and the epoxy matrix (the linear attenuation coefficient of the constituents increases with decreased incident energy [49]), which reduced the flux of photons in the detector and, consequently, increased the inspection time (around $10 \mathrm{~h}$ per scan). 
The fracture process zone (FPZ) of the DCB specimens was inspected "ex-situ" using the Versa system. Prior to inspection, $2 \times 2 \mathrm{~mm}$ (width and thickness) rectangular parallelepipeds were cut/polished from the DCB samples (away from the specimens' free-edges). A fast "scout" low-resolution inspection was performed to identify the location of the FPZ (the shape of the matchsticks and the location of the FPZ are sketched in Fig. 1). Once the region of interest had been identified, the scan set-up was altered to use a $4 \mathrm{X}$ magnifying lens and a higher-resolution scan was performed. The scanning parameters were $80 \mathrm{kV}, 87.5 \mu \mathrm{A}, 7 \mathrm{~W}, 2$ s exposure time, 2001 projections, $1.22 \mu \mathrm{m}$ pixel size and $1.24 \mathrm{~mm}$ FOV (the detector was used in the $2 \times 2$ binning mode). The source to detector and source to object distances were 82.35 and $14.90 \mathrm{~mm}$, respectively, and the specimens were rotated through $360^{\circ}$ during the acquisition of the 2001 projection images. Each inspection lasted for approximately 2 h. In total, at least 3 different $\mathrm{LTHIN}_{G_{\mathrm{IC}}}$ and $\mathrm{LV}_{G_{\mathrm{IC}}}$ specimens (some of them in several positions through the width) as well as all of the $\mathrm{LV} 2_{G_{\mathrm{IC}}} \mathrm{DCB}$ samples (two of them in multiple locations) were inspected.

During the microstructure assessment, the contrast between $\mathrm{V}_{1}$ fibres and the epoxy resin was less satisfactory than expected (despite the low incident energy, polyamide and epoxy have similar chemical constituents, plus the veils being very light). To unambiguously observe $\mathrm{V}_{1}$ fibres, one tested DCB $L V 1_{G_{\mathrm{IC}}}$ specimen was impregnated with a staining agent and subsequently scanned with the European Synchrotron Radiation Facility's ID19 Beamline (ESRF, Grenoble). The aim was that the contrast agent would impregnate and reveal the $V_{1}$ fibres interacting with the crack tip. The inspection parameters were $26 \mathrm{keV}$ X-ray energy, 90 ms exposure time, 3001 projections, $650 \mathrm{~nm}$ pixel size, approximately $2 \mathrm{~mm}$ FOV and roughly $5 \mathrm{~min}$ total inspection time (the specimens were rotated through $360^{\circ}$ during the acquisition of the 3001 projection images).

To facilitate the understanding of the images, some of the $\mu \mathrm{CT}$ stacks were post-processed using "Trainable Weka Segmentation" (a machine learning plugin from Image J [50]). The purpose was to classify the constituents of each material using a 
consistent colour code (Fig. 2): yellow for the $0^{\circ}$ carbon fibres, cyan for the $\pm 45^{\circ}$ carbon fibres, orange for the $90^{\circ}$ carbon fibres, green for the NCF stitching yarn fibres, purple for the $V_{1}$ veil fibres, red for the $V_{2}$ veil fibres and black for the cracks within the DCB specimens. It is worth noting that, despite their $\mu \mathrm{CT}$ low contrast, the shape of the $V_{1}$ fibres could be recognised because of the unequivocal debondings between the $\mathrm{V}_{1}$ fibres and the resin, which were also painted in black (compare Figs. 5 and A.1).

\section{Results}

\subsection{Microstructure}

The purpose of NCF stitches is not structural but rather to hold two layers together. However, the stitching yarns cause deviation of the fibres from their unidirectional orientations. During resin infusion, the fibre-free regions provide preferential flow paths, resulting in the so-called "resin pockets" after laminate consolidation [51]. Fig. 3 describes the types of resin pockets induced by the 33 dtex polyester (PE) yarns that, using a warp-knitting pattern, stitch together the layers of the $\left(0^{\circ} / \pm 45^{\circ}\right)$ C-PLY ${ }^{\mathrm{TM}}$ NCFs. For clarity, $\mu \mathrm{CT}$ images were taken from a $\left[\left(45^{\circ} / 0^{\circ}\right) /\left(-45^{\circ} / 90^{\circ}\right)\right]_{2 s}$ laminate made with standard-ply C-PLY ${ }^{\mathrm{TM}}$ NCFs (the size of the resin pockets increases with increased ply-thickness [19]). The orientation of the resin pockets follows the fibre orientation of the stitched ply forming, in the $\pm 45^{\circ}$ layers, a "resin ellipsoid" (also known as "fish eye" [52]). In the $0^{\circ}$ ply, the overlapping of several distortions creates a "resin channel" that separates the $0^{\circ}$ tows.

Figs. 4-8 illustrate the post-processed $\mu \mathrm{CT}$ inspections of the pristine $\mathrm{LTHIN}_{\mathrm{IP}}$, $L V 1_{\mathrm{IP}}$ and $\mathrm{LV} 2_{\mathrm{IP}}$ specimens (for comparative purposes, the corresponding raw images are included in Appendix A). The tomographies revealed no evidence of porosity in any of the laminates. Away from resin pockets, LTHIN ${ }_{\text {IP }}$ presented a closely packed microstructure (Fig. 4). In contrast, interleaving $\mathrm{V}_{1}$ (the veil with a higher fibre diameter and a more "open" architecture) increased the thickness of the resin rich interfaces (Fig. 5). V 1 fibres consistently displayed debonding with the surrounding 
matrix (refer to the black decohesions in Fig. 5). In addition, some of the $\mathrm{V}_{1}$ fibres deformed the adjacent carbon plies (Fig. 6) - the fibre is visible because it was impregnated with a contrast agent. Interleaving $\mathrm{V}_{2}$ (the veil with the thinner fibres and a more packed architecture) only impaired the interface thickness in regions where the $\mathrm{V}_{2}$ fibres agglomerated (refer to the red fibres in Fig. 7a). Contrary to the $\mathrm{V}_{1}$ fibres, the $\mathrm{V}_{2}$ fibres did not present debonding with the surrounding resin (refer to the red fibres in Fig. 8b). Despite the melting point of $\mathrm{V}_{2}$ being slightly lower than the laminate's post-curing temperature, most of the $\mathrm{V}_{2}$ fibres conserved their initial shape after manufacture (Fig. 8b). However, the $\mathrm{V}_{2}$ fibres lying close to a carbon ply displayed multiple cracks (Fig. 8a). Finally, it is worth noting that, regardless of which material system was inspected, the stitching yarn fibres also featured debonding with the surrounding resin (for an example, refer to the green fibres in Fig 8b).

\subsection{Structural response}

Fig. 9 summarizes the tensile and compressive properties of $\mathrm{LTHIN}_{\mathrm{IP}}, \mathrm{LV}_{\mathrm{IP}}$ and $\mathrm{LV} 2_{\mathrm{IP}}$ laminates. The maximum tensile loads experienced were $49 \pm 1.40,46.60 \pm 1.90$ and $48.60 \pm 1.90 \mathrm{kN}$, respectively (where \pm means standard deviation). LV2 $2_{\mathrm{IP}}$ displayed a similar tensile strength, strain-to-failure and longitudinal modulus as that

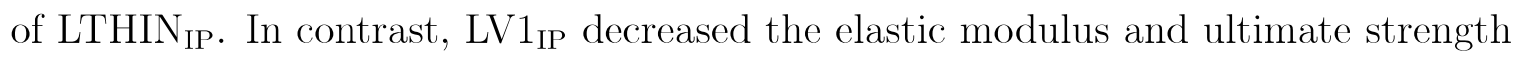
by $4 \%$ and $5 \% . \mathrm{LV} 2_{\text {IP }}$ and some of the $\mathrm{LV}_{\mathrm{IP}}$ tensile specimens changed the failure mode from a single crack to several cracks propagating across the width of the non-tabbed region. Regarding the compressive test, the maximum loads experienced by $\mathrm{LTHIN}_{\mathrm{IP}}, \mathrm{LV} 1_{\mathrm{IP}}$ and $\mathrm{LV} 2_{\mathrm{IP}}$ batches were $15.20 \pm 1,14 \pm 0.90$ and $13.10 \pm 1 \mathrm{kN}$, respectively. Interleaving both types of veil deteriorated the average compressive strength by up to $9 \%$ in the case of $\mathrm{LV} 2_{\mathrm{IP}}$ (and yet most of $\mathrm{LV} 2_{\mathrm{IP}}$ values lay within the scatter of LTHIN $\left._{I P}\right)$.

Fig. 10 presents the force response and average R-curves of the $\operatorname{LTHIN}_{G_{\mathrm{IC}}}, \mathrm{LV}_{G_{\mathrm{IC}}}$ and $\mathrm{LV} 2_{G_{\mathrm{IC}}}$ DCB specimens. Fig. 11 includes the average mode-I initiation $\left(G_{\text {Iinit }}\right)$ and propagation $\left(G_{\text {Iprop }}\right)$ interlaminar fracture toughness values. The load 
displacement curves of LTHIN $_{G_{\mathrm{IC}}}$ displayed a range of shapes and propagation forces; the curves with a lower maximum force exhibited a jagged shape (i.e. with multiple load drops), whereas those with higher propagation forces were smoother. The curves of $\mathrm{LV}_{G_{\mathrm{IC}}}$ featured a similar tendency to those of $\mathrm{LTHIN}_{G_{\mathrm{IC}}}$, albeit with higher variation and more intensified load oscillations. The force response of $\mathrm{LV} 2_{G_{\mathrm{IC}}}$ evidenced less variation and smaller load drops than those of $\operatorname{LTHIN}_{G_{\mathrm{IC}}}$ and $\mathrm{LV}_{G_{\mathrm{IC}}}$, resulting in the highest $G_{\text {Iinit }}$ and $G_{\text {Iprop }}$ of all the systems. LV $2_{G_{\text {IC }}}$ enhanced $G_{\text {Iinit }}$ and $G_{\text {Iprop }}$ by $101 \%$ and $43 \%$ compared to $\operatorname{LTHIN}_{G_{\mathrm{IC}}} \cdot \mathrm{LV}_{G_{\mathrm{IC}}}$ only improved $G_{\text {Iinit }}$ by $12 \%$.

\subsection{Fracture process zone}

Figs. 12-13 illustrate the post-processed $\mu \mathrm{CT}$ inspections performed in the FPZ of the $\mathrm{LTHIN}_{G_{\mathrm{IC}}}, \mathrm{LV} 1_{G_{\mathrm{IC}}}$ and $\mathrm{LV} 2_{G_{\mathrm{IC}}}$ DCB specimens (for the sake of comparison, the corresponding raw images are included in Appendix A). The crack grows towards the reader. In particular, Figs. 12a and 13 summarize the mode-I propagation mechanisms of LTHIN $_{G_{\text {IC }}}$ when inspected in the different y-positions of the same specimen (refer to the coordinate system defined in Fig. 1). In Fig. 12a, the crack propagates across the $0^{\circ} / 0^{\circ}$ interface (the $0^{\circ}$ carbon fibres and the crack are coloured yellow and black, respectively). In Fig. 13, the crack deviates from the $0^{\circ} / 0^{\circ}$ interface through the debonding of the stitching yarn fibres (the yarn fibres are coloured green). The right part of Fig. 13 displays how the unbalanced crack preferred to propagate inside a $0^{\circ}$ carbon tow rather than continuing to face the stitching yarn fibres of the $0^{\circ} / 0^{\circ}$ interface. Regarding $\mathrm{LV}_{G_{\text {IC }}}$, the crack interacted with both $\mathrm{V}_{1}$ fibres and stitching yarn fibres and yet it was confined to the interfaces (Fig. 12b). ( $\mathrm{V}_{1}$ fibres are coloured purple). In contrast, the crack of $L V 2_{G_{\mathrm{IC}}}$ propagated inside the $0^{\circ}$ layers (Fig. 12c) - except when it interacted with the NCF yarn fibres.

\section{Discussion}

The laminates interleaved with $\mathrm{V}_{1}$ or $\mathrm{V}_{2}$ veils presented no evidence of porosity as well as the same nominal thickness and fibre volume fraction as the non-interleaved 
baseline laminate (e.g. the average thicknesses of $L T H I N N_{I P}, L V 1_{I P}$ and $L V 2_{\text {IP }}$ tested specimens were $2.30 \pm 0.20,2.20$ and 2.20, and their average fibre volume fractions were $53.50 \pm 1.60 \%, 53.50 \pm 1.70 \%$ and $53.70 \pm 1.30 \%$, respectively). Laminate thickness was preserved because of the combination of low veil fibre areal weight $\left(4 \mathrm{~g} / \mathrm{m}^{2}\right)$ and RTM manufacturing: all of the laminates fitted within the same mould. Incorporating the same amount of carbon fibre within a fixed volume results in a similar fibre volume fraction as measured by acid digestion methods [45]. The lack of porosity is also attributed to the low fibre areal weight of the veils (light veils allow through-thickness resin infusion $[34,53])$.

Interleaving $\mathrm{V}_{1}$ increased the thickness of the resin interfaces. In contrast, interleaving $V_{2}$ only increased interface thickness in regions where $V_{2}$ fibres agglomerated (compare Figs. 4-5 and 7). Despite the melting temperature of $\mathrm{V}_{2}$ being slightly lower than the laminate's post-curing temperature, most of the $\mathrm{V}_{2}$ fibres maintained their original shape after manufacture (refer to the red fibres in Fig. 8b). However, $\mathrm{V}_{2}$ fibres lying close to a carbon tow displayed multiple cracks (Fig. 8a). $\mathrm{LV}_{1}$ IP accumulates resin in the interfaces because the fibre diameter of $\mathrm{V}_{1}(37 \mu \mathrm{m})$ is much higher than the interface thickness of LTHIN $_{\text {IP }}$ (approximately $10 \mu \mathrm{m}$ ). $\mathrm{V}_{2}$ fibres conserve their inital shape because of the competition between fibre melting and resin gelification (when $\mathrm{V}_{2}$ fibres start to yield, the resin is viscous enough to lock in the position of the fibres [21]). The cracks in veils $\mathrm{V}_{2}$ develop because the stiff carbon tows provide extra-stiffness to the system and constraint further the thermal expansion of $\mathrm{V}_{2}$ fibres (thermal stresses dissipate in the form of cracks). Therefore, the only possible movement is $\mathrm{V}_{2}$ fibres diffusing along with resin infusion (before curing $[21,22]$ ), which would explain the agglomerations observed in LV2 $2_{\text {IP }}$ (Fig. 7a).

$\mathrm{V}_{1}$ fibres consistently displayed debonding with the surrounding matrix (refer to the purple fibres in Figs. 5-6). The same observation applied for NCF stitching yarn fibres (e.g. the green fibres in Fig. 8b). In contrast, the $\mathrm{V}_{2}$ fibres displayed almost no debonding with the resin (e.g. the red fibres in Fig. 8b). Based on the observations, it is clear that $\mathrm{V}_{2}$ fibres display a qualitatively higher adhesion with epoxy than $\mathrm{V}_{1}$ or 
stitching yarn fibres do.

LV2 $2_{\mathrm{IP}}$ displayed a similar tensile strength, strain-to-failure and longitudinal modulus as that of $\mathrm{LTHIN}_{\mathrm{IP}}$. In contrast, $\mathrm{LV} 1_{\mathrm{IP}}$ reduced the tensile modulus and ultimate strength by $4 \%$ and $5 \%$ (Fig 9). The tendencies observed are connected to the microstructure of the materials. The tensile properties of LV $2_{\mathrm{IP}}$ are similar to

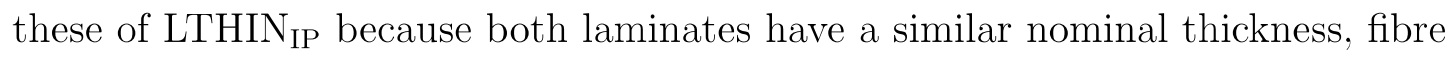
volume fraction and (overall) interface thickness, which is not the case of $\mathrm{LV} 1_{\mathrm{IP}}$ (the thick $\mathrm{V}_{1}$ fibre increase significantly interface thickness, Figs. 5-6).

Both $L V 1_{I P}$ and $L V 2_{\text {IP }}$ decreased the compressive strength of the baseline laminate (Fig. 9). The compressive strength depends on the ability of the matrix to prevent fibre buckling [34]. Compressive loads rotate the carbon fibres and generate shear stresses that, in turn, further kink the fibres until catastrophic buckling occurs [54]. Therefore, interleaving thermoplastic veils likely decreased the pristine shear strength of the matrix at the low strain rates of the test $[38,55]$. However, it is worth noting that $\mathrm{LV} 2_{\mathrm{IP}}$ enhanced CAI strength by up to $28 \%$ for impact at $14 \mathrm{~J}$ [38]. The effect interleaving has on matrix shear strength will be addressed in further investigations. $\mathrm{LTHIN}_{G_{\mathrm{IC}}}, \mathrm{LV} 1_{G_{\mathrm{IC}}}$ and $\mathrm{LV} 2_{G_{\mathrm{IC}}}$ featured different crack propagation mechanisms (Figs. 12-13). Mode-I crack growth is mainly governed by the adhesion between the fibres (the stitching yarn fibres, the $\mathrm{V}_{1}$ fibres or the $\mathrm{V}_{2}$ fibres) and the matrix [33]. Fibres with a suspected low adhesion (the yarn fibres and the $\mathrm{V}_{1}$ fibres) promote crack propagation by fibre-resin debonding [56]. Fibres with a suspected higher adhesion (the $\mathrm{V}_{2}$ fibres) avoid interacting with the crack $[29,56]$. Therefore, it seems logical that the crack of LTHIN $_{G_{\mathrm{IC}}}$ interacts with the yarn fibres (the green fibres in Fig. 13), the crack of $\mathrm{LV}_{G_{\mathrm{IC}}}$ interacts with the $\mathrm{V}_{1}$ fibres (the purple fibre in Fig. $12 \mathrm{~b}$ ) and the crack of $\mathrm{LV} 2_{G_{\mathrm{IC}}}$ deflects away from the veil (particularly into the $0^{\circ}$ layers, Fig. 12c). As a result of these interactions, the crack of $L V 1_{G_{\mathrm{IC}}}$ confines itself to the $0^{\circ} / 0^{\circ}$ interface (Fig. 12b), the crack of $L V 2_{G_{\text {IC }}}$ propagates across the $0^{\circ}$ plies (Fig. 12c) and the crack of $\operatorname{LTHIN}_{G_{\text {IC }}}$ meanders among the $0^{\circ} / 0^{\circ}$ interface and the $0^{\circ}$ layers (some of the stitching yarns diverted crack propagation from the resin interlayer 
into the $0^{\circ}$ plies, Figs. 12a and 13 ).

$\mathrm{LV}_{G_{\mathrm{IC}}}$ enhanced $G_{\text {Iinit }}$ and $G_{\text {Iprop }}$ by $101 \%$ and $43 \%$ compared to LTHIN $_{G_{\text {IC }}}$, whereas $\mathrm{LV}_{G_{\mathrm{IC}}}$ only enhanced $G_{\text {Iinit }}$ by $12 \%$ (Fig. 11). The FPZ observations suggest that $\mathrm{V}_{1}$ fibres dissipate fracture energy as they interact with the crack (Fig. 12b). Dissipation mechanisms probably include fibre deformation and fibre pull-out from the matrix [33]. However, $L V 1_{G_{\mathrm{IC}}}$ did not affect the the baseline $G_{\text {Iprop }}$ because of the low number of $V_{1}$ fibres interacting with the crack (the surface area covered by $V_{1}$ was only $22 \%$ ) [23]. The $101 \% G_{\text {Iinit }}$ improvement displayed by $\mathrm{LV} 2_{G_{\mathrm{IC}}}$ is explained if, during initiation, the crack required extra energy to circumvent $V_{2}$ fibres and penetrate into the $0^{\circ}$ plies. This explanation correlates with the observations of the FPZ and would justify why the improvement of $G_{\text {Iprop }}$ is smaller than that of $G_{\text {Iinit }}$ (43\% versus 101\%): intralaminar crack propagation is independent of $\mathrm{V}_{2}$ fibres (Fig. $12 \mathrm{c})$.

The tendencies observed in $\mathrm{LV} 2_{G_{\mathrm{IC}}}$ are contrary to standard-ply studies where the veil fibres with higher adhesion provide the lower $\mathrm{G}_{\mathrm{IC}}$ values. Saz-Orozco et al. [29] reported that a $45 \mathrm{~g} / \mathrm{m}^{2}$ polyethylene terephtalate veil deflected crack initiation from the resin interlayer (full of veil) to the interfacial region between resin and structural fibres (depleted of veil), which had no effect on $G_{\text {Iprop }}$ and decreased $G_{\text {Iinit }}$ by $32 \%$. The difference is that $\mathrm{LV} 2_{G_{\mathrm{IC}}}$ deviated crack propagation not to the interfacial but to the intralaminar region (i.e. the $0^{\circ}$ plies in Fig 12c), which increased the initiation energy. This could be the consequence of several factors such as the smaller interface thickness of thin-plies, the shape distortions induced by NCF stitches and the low fibre areal weight and fibre diameter of $\mathrm{V}_{2}$ preventing resin accumulation in the interfaces (there is no such resin layer depleted of veil).

Overall, interleaving the veil with lower fibre diameter $\left(\mathrm{V}_{2}\right)$ resulted in a reasonable trade-off between $G_{\mathrm{IC}}$ and in-plane mechanical properties - together with an increase of the baseline CAI strength [38]. Tsotsis [21] reasoned that, for a given veil fibre areal weight, reducing veil fibre diameter increases the surface area covered by veil fibres, which potentially increases the veil's performance (there is a higher number of 
veil filaments interacting with crack propagation). This is in line with the promising results displayed by the increasingly attractive "nano-fibre" veils: a new generation of thermoplastic reinforcements whose fibre diameter is approximately 1000 times smaller than that of $\mathrm{V}_{2}$ [57-61]. For an example, the PA nano-fibre veils used by Beckermann [58] or Beylergil et al. [59] improved interlaminar fracture toughness and several mechanical properties with no significant increase of laminate thickness (veil fibre diameter was not reported for Beckermann and $87 \mathrm{~nm}$ for Beylergil). On the negative side, the main factor limiting the use of nano-veils on an industrial scale is their cost [60]. The price of the polypropylene micro-fibre veils used by Zhu [62] was around $7 € / \mathrm{Kg}$. In contrast, the PA nano-fibre veil recently developed by Beckermann [58] would have raised the costs by three orders of magnitude (approximately $7000 € / \mathrm{Kg}[63]$ ). In this sense, $\mathrm{V}_{2}$ micro-fibre veil offers the perfect balance between price, mechanical properties, commercial availability and ease of manufacture, ideal to toughen aeronautical thin-ply laminates — for further information regarding the mechanical response of thermoplastic nano-fibre veils, the reader is referred to the following references [60, 64-74].

\section{Conclusions}

This study interleaved two different types of $4 \mathrm{~g} / \mathrm{m}^{2}$ co-polyamide veils (named $\mathrm{V}_{1}$ and $\mathrm{V}_{2}$ ) into a thin-ply quasi-isotropic baseline laminate. The combination of the low veil fibre areal weight and a resin transfer mould was crucial to preserve laminate thickness and fibre volume fraction: baseline and interleaved configurations fitted within the same mould. None of the laminates displayed porosity, evidencing that light veils allow through-the-thickness resin flow.

Given the similar laminate thickness, the veil fibre diameter was the key parameter in determining the tensile properties. The veil with thicker fibres $\left(V_{1}\right)$ increased the thickness of the resin interfaces and reduced the tensile properties (elastic modulus and ultimate strength were reduced by $4 \%$ and $5 \%$ ). In contrast, the veil with the thinner fibres $\left(\mathrm{V}_{2}\right)$ avoided resin accumulation in the interfaces and displayed the 
same tensile strength, strain-to-failure and longitudinal modulus as the baseline laminate did. Both types of veil decreased compressive strength by up to $9 \%$ because of an increase in the ductile phase surrounding the carbon plies, which favours fibre buckling.

Mode-I interlaminar crack propagation was mainly controlled by the adhesion between fibres (the non-crimp fabric yarn fibres, the $V_{1}$ fibres and the $V_{2}$ fibres) and the resin. Fibres with a suspected low adhesion (the yarn fibres and the $V_{1}$ fibres) promoted crack growth by debonding from the resin. Fibres with a higher adhesion (the $\mathrm{V}_{2}$ fibres) deviated crack growth away from the veil. In the non-interleaved laminate, the crack deflected from the $0^{\circ} / 0^{\circ}$ interface through debonding of the stitching yarn fibres. In the laminate interleaved with $\mathrm{V}_{1}$, the crack confined into the $0^{\circ} / 0^{\circ}$ interface through interaction with the $\mathrm{V}_{1}$ fibres (fracture toughness was not improved because the veil $\mathrm{V}_{1}$ contained few fibres). In the laminate interleaved with $\mathrm{V}_{2}$, the crack deviated from the $0^{\circ} / 0^{\circ}$ interface to the surrounding $0^{\circ}$ plies which, in the material system studied, resulted in the highest mode-I initiation and propagation interlaminar fracture toughness $(101 \%$ and $43 \%$ increase compared to the non-interleaved laminate).

\section{Acknowledgements}

The authors thank Chomarat (Le Cheylard, France) for manufacturing the materials used in this study. We acknowledge the support of Dr. Imma Boada and her team (Graphics and Imaging Laboratory, University of Girona) for providing the software Starviewer, the 3D viewer used to render the tomographic slices. We also acknowledge Professor Ian Sinclair and Dr. Mark Mavrogordato (Faculty of Engineering and Physical Sciences, University of Southampton) for useful discussions. Thanks to the European Synchrotron Radiation Facility and, in particular, to Lukas Helfen for assistance in using beamline ID19. We also extend our appreciation to the Spanish Ministerio de Ciencia, Innovación y Universidades for the financial support under the contract RTI2018-097880-B-I00. The first author is particularly grateful for 
the support received from the Secretaria d'Universitats i Recerca del Departament d'Empresa i Coneixement de la Generalitat de Catalunya through the pre-doctoral grant 2016FI_B_00551, co-funded by the Fondo Social Europeo (FSE).

\section{Appendix A}

For comparative purposes, Figs A.1-A.5 illustrate several unprocessed $\mu \mathrm{CT}$ images. 


\section{References}

[1] N. H. Nash, T. M. Young, P. T. McGrail, W. F. Stanley, Inclusion of a thermoplastic phase to improve impact and post-impact performances of carbon fibre reinforced thermosetting composites - A review, Materials and Design 85 (2015) 582-597. doi:10.1016/j.matdes.2015.07.001.

[2] S. Sihn, R. Kim, K. Kawabe, S. Tsai, Experimental studies of thin-ply laminated composites, Composites Science and Technology 67 (6) (2007) 996-1008. doi:10.1016/j.compscitech.2006.06.008.

[3] T. Yokozeki, Y. Aoki, T. Ogasawara, Experimental characterization of strength and damage resistance properties of thin-ply carbon fiber/toughened epoxy laminates, Composite Structures 82 (3) (2008) 382-389. doi:10.1016/j.compstruct. 2007.01.015.

[4] J. Moon, M. Kim, C. Kim, S. Bhowmik, Improvement of tensile properties of CFRP composites under LEO space environment by applying MWNTs and thin-ply, Composites Part A: Applied Science and Manufacturing 42 (6) (2011) 694-701. doi:10.1016/j.compositesa.2011.02.011.

[5] A. Arteiro, G. Catalanotti, J. Xavier, P. Camanho, Notched response of non-crimp fabric thin-ply laminates, Composites Science and Technology 79 (2013) 97-114. doi:10.1016/j.compscitech.2013.02.001.

[6] R. Amacher, J. Cugnoni, J. Botsis, L. Sorensen, W. Smith, C. Dransfeld, Thin ply composites: Experimental characterization and modeling of size-effects, Composites Science and Technology 101 (2014) 121-132. doi:10.1016/j.compscitech.2014.06.027.

[7] H. El-Dessouky, C. Lawrence, Ultra-lightweight carbon fibre/thermoplastic composite material using spread tow technology, Composites Part B: Engineering 50 (50) (2013) 91-97. doi:10.1016/j. compositesb.2013.01.026. 
[8] G. Guillamet, A. Turon, J. Costa, J. Renart, P. Linde, J. Mayugo, Damage occurrence at edges of non-crimp-fabric thin-ply laminates under off-axis uniaxial loading, Composites Science and Technology 98 (2014) 44-50. doi:10.1016/j.compscitech.2014.04.014.

[9] C. Furtado, A. Arteiro, G. Catalanotti, J. Xavier, P. P. Camanho, Selective ply-level hybridisation for improved notched response of composite laminates, Composite Structures 145 (2016) 1-14. doi:10.1016/j.compstruct.2016.02.050.

[10] A. Arteiro, G. Catalanotti, J. Xavier, P. Linde, P. P. Camanho, Effect of tow thickness on the structural response of aerospace-grade spread-tow fabrics, Composite Structures 179 (2017) 208-223. doi:10.1016/j.compstruct.2017.06.047.

[11] Y. Ho, H. Sasayama, J. Yanagimoto, Mechanical properties and drawing process of multilayer carbon-fiber-reinforced plastic sheets with various prepreg thicknesses, Advances in Mechanical Engineering 9 (3) (2017) 1-12. doi:10.1177/1687814017692695.

[12] J. Cugnoni, R. Amacher, S. Kohler, J. Brunner, E. Kramer, C. Dransfeld, W. Smith, K. Scobbie, L. Sorensen, J. Botsis, Towards aerospace grade thin-ply composites: Effect of ply thickness, fibre, matrix and interlayer toughening on strength and damage tolerance, Composites Science and Technology 168 (10) (2018) 467-477. doi:10.1016/j. compscitech.2018.08.037.

[13] C. Huang, S. Ju, M. He, Q. Zheng, Y. He, J. Xiao, J. Zhang, D. Jiang, Identification of failure modes of composite thin-ply laminates containing circular hole under tension by acoustic emission signals, Composite Structures 206 (2018) 70-79. doi:10.1016/j. compstruct.2018.08.019.

[14] E. Kalfon-Cohen, R. Kopp, C. Furtado, X. Ni, A. Arteiro, G. Borstnar, 
M. Mavrogordato, I. Sinclair, S. Spearing, P. Camanho, B. Wardle, Synergetic effects of thin plies and aligned carbon nanotube interlaminar reinforcement in composite laminates, Composites Science and Technology 166 (2018) 160-168. doi:10.1016/j. compscitech.2018.01.007.

[15] A. Wagih, P. Maimí, N. Blanco, S. García-Rodríguez, G. Guillamet, R. Issac, A. Turon, J. Costa, Improving damage resistance and load capacity of thin-ply laminates using ply clustering and small mismatch angles, Composites Part A: Applied Science and Manufacturing 117 (April 2018) (2019) 76-91. doi:10.1016/j.compositesa.2018.11.008.

[16] R. Teixeira, S. Pinho, P. Robinson, Thickness-dependence of the translaminar fracture toughness: Experimental study using thin-ply composites, Composites Part A: Applied Science and Manufacturing 90 (2016) 33-44. doi:10.1016/j.compositesa.2016.05.031.

[17] G. Frossard, J. Cugnoni, T. Gmür, J. Botsis, Mode I Interlaminar Fracture of Carbon Epoxy Laminates: Effects of Ply Thickness, Composites Part A: Applied Science and Manufacturing 91 (1) (2016) 1-8. doi:10.1016/j.compositesa.2016.09.009.

[18] G. Frossard, J. Cugnoni, T. Gmür, J. Botsis, Ply thickness dependence of the intralaminar fracture in thin-ply carbon-epoxy laminates, Composites Part A: Applied Science and Manufacturing 109 (2018) 95-104. doi:10.1016/j.compositesa.2018.03.001.

[19] S. García-Rodríguez, J. Costa, A. Bardera, V. Singery, D. Trias, A 3D tomographic investigation to elucidate the low-velocity impact resistance, tolerance and damage sequence of thin non-crimp fabric laminates: effect of ply-thickness, Composites Part A: Applied Science and Manufacturing 113 (July) (2018) 53-65. doi:10.1016/j. compositesa.2018.07.013. 
[20] A. Wagih, P. Maimí, E. González, N. Blanco, J. Sainz de Aja, F. de la Escalera, R. Olsson, E. Alvarez, Damage sequence in thin-ply composite laminates under out-of-plane loading, Composites Part A: Applied Science and Manufacturing 87 (2016) 66-77. doi:10.1016/j.compositesa.2016.04.010.

[21] T. Tsotsis, Interlayer toughening of composite materials, Polymer Composites 30 (1) (2009) 70-86. doi:10.1002/pc.20535.

[22] M. Kuwata, P. J. Hogg, Interlaminar toughness of interleaved CFRP using non-woven veils: Part 1. Mode-I testing, Composites Part A: Applied Science and Manufacturing 42 (10) (2011) 1551-1559. doi:10.1016/j.compositesa.2011.07.016.

[23] V. Ramírez, P. Hogg, W. Sampson, The influence of the nonwoven veil architectures on interlaminar fracture toughness of interleaved composites, Composites Science and Technology 110 (2015) 103-110. doi:10.1016/j.compscitech.2015.01.016.

[24] M. Sohn, X. Hu, Processing of carbon-fibre/epoxy composites with cost-effective interlaminar reinforcement, Composites Science and Technology 58 (2) (1998) 211-220. doi : 10.1016/S0266-3538(97)00114-0.

[25] M. Guo, X. Yi, G. Liu, L. Liu, Simultaneously increasing the electrical conductivity and fracture toughness of carbon-fiber composites by using silver nanowires-loaded interleaves, Composites Science and Technology 97 (2014) 27-33. doi:10.1016/j.compscitech.2014.03.020.

[26] K. O'Donovan, D. Ray, M. McCarthy, Toughening effects of interleaved nylon veils on glass fabric/low-styrene-emission unsaturated polyester resin composites, Journal of Applied Polymer Science 132 (2014) 1-9. doi:10.1002/app. 41462.

[27] N. Nash, D. Ray, T. Young, W. Stanley, The influence of hydrothermal conditioning on the Mode-I, thermal and flexural properties of 
Carbon/Benzoxazine composites with a thermoplastic toughening interlayer, Composites Part A: Applied Science and Manufacturing 76 (2015) 135-144. doi:10.1016/j.compositesa.2015.04.023.

[28] N. Ni, Y. Wen, D. He, X. Yi, T. Zhang, Y. Xu, High damping and high stiffness CFRP composites with aramid non-woven fabric interlayers, Composites Science and Technology 117 (2015) 92-99. doi:10.1016/j.compscitech.2015.06.002.

[29] B. Saz-Orozco, D. Ray, W. F. Stanley, Effect of Thermoplastic Veils on Interlaminar Fracture Toughness of a Glass Fiber/Vinyl Ester Composite, Polymers and Polymer Composites 16 (2) (2015) 101-113. doi:10.1002/pc. 23840 .

[30] N. H. Nash, T. M. Young, W. F. Stanley, The reversibility of Mode-I and -II interlaminar fracture toughness after hydrothermal aging of Carbon/Benzoxazine composites with a thermoplastic toughening interlayer, Composite Structures 152 (2016) 558-567. doi:10.1016/j.compstruct.2016.05.086.

[31] E. Barjasteh, C. Sutanto, T. Reddy, J. Vinh, A graphene/graphite-based conductive polyamide 12 interlayer for increasing the fracture toughness and conductivity of carbon-fiber composites, Journal of Composite Materials 51 (51) (2017) 2879-2887. doi:10.1177/0021998317705707.

[32] B. Beylergil, M. Tanoglu, E. Aktas, Effect of polyamide-6,6 (PA 66) nonwoven veils on the mechanical performance of carbon fiber/epoxy composites, Composite Structures 194 (2018) 21-35. doi:10.1016/j.compstruct.2018.03.097.

[33] M. Kuwata, Mechanisms of interlaminar fracture toughness using non-woven veils as interleaf materials. Ph.D. dissertation submitted to the School of Engineering and Materials Science, Queen Mary, University of London. (February 2010). URL https://qmro.qmul.ac.uk/xmlui/handle/123456789/2220 
[34] S. Miller, G. Roberts, L. Kohlman, P. Heimann, J. Pereira, R. Ruggeri, R. Martin, L. McCorkle, Impact behavior of composite fan blade leading edge subcomponent with thermoplastic polyurethane interleave. 20th International Conference on Composite Materials (Copenhagen, 19-24th July 2015).

[35] K. Fitzmaurice, D. Ray, M. McCarthy, PET interleaving veils for improved fracture toughness of glass fibre/low-styrene-emission unsaturated polyester resin composites, Journal of Applied Polymer Science 133 (3) (2015) 1-8. doi:10.1002/app. 42877.

[36] R. Ritchie, The conflicts between strength and toughness, Nature Materials 10 (11) (2011) 817-822. doi:10.1038/nmat3115.

[37] D. Wong, H. Zhang, E. Bilotti, T. Peijs, Interlaminar toughening of woven fabric carbon/epoxy composite laminates using hybrid aramid/phenoxy interleaves, Composites Part A: Applied Science and Manufacturing 101 (2017) 151-159. doi:10.1016/j.compositesa.2017.06.001.

[38] S. García-Rodríguez, J. Costa, V. Singery, I. Boada, J. A. Mayugo, The effect interleaving has on thin-ply non-crimp fabric laminate impact response: X-ray tomography investigation, Composites Part A: Applied Science and Manufacturing 107 (November 2017) (2017) 409-420. doi:10.1016/j.compositesa.2018.01.023.

[39] M. Papila, Design of and with thin-ply non-crimp fabric (NCF) as building blocks for composites, Science and Engineering of Composite Materials (2016) 1-16doi:10.1515/secm-2015-0386.

[40] Image J: Image Processing and Analysis in Java, URL: https://imagej.nih.gov/ij/.

[41] ASTM Standard D6641/D6641M-14, Standard Test Method for Compressive Properties of Polymer Matrix Composite Materials Using a Combined Loading 
Compression (CLC) Test Fixture. ASTM International, West Conshohocken, PA (2014). URL: www.astm.org.

[42] ASTM Standard D3039/D3039M-14, Standard Test Method for Tensile Properties of Polymer Matrix Composite Materials. ASTM International, West Conshohocken, PA (2014). URL: www.astm.org.

[43] ASTM Standard D5528/D5528M-13, Standard Test Method for Mode I Interlaminar Fracture Toughness of Unidirectional Fiber-Reinforced Polymer Matrix Composites. ASTM International, West Conshohocken, PA (2013). URL: www.astm.org.

[44] ISO Standard 15024, Fibre-reinforced plastic composites - Determination of mode II fracture resistance for unidirectionally reinforced materials using the calibrated end-loaded split (C-ELS). Geneva, Switzerland (2011). URL: www.iso.org.

[45] European standard DIN EN 2564:1998, Aerospace series, Carbon fibre laminates, Determination of the fibre-, resin- and void contents, Deutsches Institut für Normung (DIN), Berlin, Germany (1998).

[46] J. Renart, N. Blanco, E. Pajares, J. Costa, S. Lazcano, G. Santacruz, Side Clamped Beam (SCB) hinge system for delamination tests in beam-type composite specimens, Composites Science and Technology 71 (8) (2011) 1023-1029. doi:10.1016/j. compscitech.2010.10.005.

[47] ISO Standard 15024, Fibre-reinforced plastic composites - Determination of mode I interlaminar fracture toughness, Gic, for unidirectionally reinforced materials. Geneva, Switzerland (2011). URL: www.iso.org.

[48] AITM1-0005 Airbus Test Method. Carbon Fibre Reinforced Plastics. Determination of interlaminar fracture toughness energy ( G1C Test). (2015) AIRBUS S.A.S Engineering Directorate 31707 Blagnac Cedex FRANCE. 
[49] S. C. Garcea, Y. Wang, P. J. Withers, X-ray computed tomography of polymer composites, Composites Science and Technology 156 (2018) 305-319.

doi:10.1016/j.compscitech.2017.10.023.

[50] Trainable Weka Segmentation plugin, URL:

https://imagej.net/Trainable_Weka_Segmentation.

[51] S. Lomov, E. Belov, T. Bischoff, S. Ghosh, T. Chi, I. Verpoest, Carbon composites based on multiaxial multiply stitched preforms. Part 1. Geometry of the preform, Composites - Part A: Applied Science and Manufacturing 33 (2002) 1171-1183. doi:10.1016/S1359-835X(02)00090-8.

[52] C. Lekakou, S. Edwards, G. Bell, S. C. Amico, Computer modelling for the prediction of the in-plane permeability of non-crimp stitch bonded fabrics, Composites Part A: Applied Science and Manufacturing 37 (2006) 820-825. doi:10.1016/j.compositesa.2005.04.002.

[53] N. H. Nash, T. M. Young, W. F. Stanley, An investigation of the damage tolerance of carbon/Benzoxazine composites with a thermoplastic toughening interlayer, Composite Structures 147 (2016) 25-32. doi:10.1016/j.compstruct.2016.03.015.

[54] S. Pinho, L. Iannucci, P. Robinson, Physically based failure models and criteria for laminated fibre-reinforced composites with emphasis on fibre kinking. Part I: Development, Composites Part A: Applied Science and Manufacturing 37 (5) (2006) 63-73. doi:10.1016/j.compositesa.2005.04.016.

[55] D. Bull, S. Spearing, I. Sinclair, Investigation of the response to low velocity impact and quasi-static indentation loading of particle-toughened carbon-fibre composite materials, Composites Part A: Applied Science and Manufacturing 74 (2015) 38-46. doi:10.1016/j.compositesa.2015.03.016. 
[56] G. Borstnar, M. Mavrogordato, L. Helfen, I. Sinclair, S. Spearing, Interlaminar fracture micro-mechanisms in toughened carbon fibre reinforced plastics investigated via synchrotron radiation computed tomography and laminography, Composites Part A: Applied Science and Manufacturing 71 (2015) 176-183. doi:10.1016/j.compositesa.2015.01.012.

[57] G. Beckermann, K. Pickering, Mode I and Mode II interlaminar fracture toughness of composite laminates interleaved with electrospun nanofibre veils, Composites Part A: Applied Science and Manufacturing 72 (2015) 11-21. doi:10.1016/j.compositesa.2015.01.028.

[58] G. W. Beckermann, Nanofiber interleaving veils for improving the performance of composite laminates, Reinforced Plastics 61 (5) (2017) 289-293. doi:10.1016/j.repl.2017.03.006.

[59] B. Beylergil, M. Tanoglu, E. Aktas, Enhancement of interlaminar fracture toughness of carbon fiber-epoxy composites using polyamide-6,6 electrospun nanofibers, Journal of Applied Polymer Science 134 (35) (2017) 1-12. doi:10.1002/app. 45244.

[60] R. Palazzetti, A. Zucchelli, Electrospun nanofibers as reinforcement for composite laminates materials A review, Composite Structures 182 (August) (2017) 711-727. doi:10.1016/j. compstruct.2017.09.021.

[61] L. Daelemans, A. Cohades, T. Meireman, J. Beckx, S. Spronk, M. Kersemans, I. De Baere, H. Rahier, V. Michaud, W. Van Paepegem, K. De Clerck, Electrospun nanofibrous interleaves for improved low velocity impact resistance of glass fibre reinforced composite laminates, Materials and Design 141 (2018) 170-184. doi:10.1016/j.matdes .2017.12.045.

[62] L. Zhu, Investigations on damage resistance of carbon fiber composite panels 
toughened using veils, Chinese Journal of Aeronautics 26 (3) (2013) 807-813. doi:10.1016/j.cja.2013.05.006.

[63] The first commercially available nano-fibre veil: https://www.xantulayr.com.

[64] K. Shivakumar, S. Lingaiah, H. Chen, P. Akangah, G. Swaminathan, L. Russell, Polymer Nanofabric Interleaved Composite Laminates, AIAA Journal 47 (7) (2009) 1723-1729. doi:10.2514/1.41791.

[65] P. Akangah, S. Lingaiah, K. Shivakumar, Effect of Nylon-66 nano-fiber interleaving on impact damage resistance of epoxy/carbon fiber composite laminates, Composite Structures 92 (6) (2010) 1432-1439. doi:10.1016/j.compstruct.2009.11.009.

[66] R. Palazzetti, A. Zucchelli, C. Gualandi, M. L. Focarete, L. Donati, G. Minak, S. Ramakrishna, Influence of electrospun Nylon 6,6 nanofibrous mats on the interlaminar properties of Gr-epoxy composite laminates, Composite Structures 94 (2) (2012) 571-579. doi:10.1016/j.compstruct.2011.08.019.

[67] R. Palazzetti, A. Zucchelli, I. Trendafilova, The self-reinforcing effect of Nylon 6,6 nano-fibres on CFRP laminates subjected to low velocity impact, Composite Structures 106 (2013) 661-671. doi:10.1016/j.compstruct.2013.07.021.

[68] T. Brugo, R. Palazzetti, The effect of thickness of Nylon 6,6 nanofibrous mat on Modes I-II fracture mechanics of UD and woven composite laminates, Composite Structures 154 (2016) 172-178. doi:10.1016/j.compstruct.2016.07.034.

[69] L. Daelemans, S. van der Heijden, I. De Baere, H. Rahier, W. Van Paepegem, K. De Clerck, Nanofibre bridging as a toughening mechanism in carbon/epoxy composite laminates interleaved with electrospun polyamide nanofibrous veils, Composites Science and Technology 117 (2015) 244-256. doi:10.1016/j.compscitech.2015.06.021. 
[70] L. Daelemans, S. Van Der Heijden, I. De Baere, H. Rahier, W. Van Paepegem, K. De Clerck, Damage-Resistant Composites Using Electrospun Nanofibers: A Multiscale Analysis of the Toughening Mechanisms, ACS Applied Materials and Interfaces 8 (18) (2016) 11806-11818. doi:10.1021/acsami.6b02247.

[71] H. Saghafi, A. Zucchelli, R. Palazzetti, G. Minak, The effect of interleaved composite nanofibrous mats on delamination behavior of polymeric composite materials, Composite Structures 109 (1) (2014) 41-47. doi:10.1016/j.compstruct.2013.10.039.

[72] H. Saghafi, R. Palazzetti, A. Zucchelli, G. Minak, Influence of electrospun nanofibers on the interlaminar properties of unidirectional epoxy resin/glass fiber composite laminates, Journal of Reinforced Plastics and Composites 34 (11) (2015) 907-914. doi:10.1177/0731684415584635.

[73] T. Brugo, G. Minak, A. Zucchelli, X. T. Yan, J. Belcari, H. Saghafi, R. Palazzetti, Study on Mode I fatigue behaviour of Nylon 6,6 nanoreinforced CFRP laminates, Composite Structures 164 (2017) 51-57. doi:10.1016/j.compstruct.2016.12.070.

[74] C. Monteserín, M. Blanco, N. Murillo, A. Pérez-Márquez, J. Maudes, J. Gayoso, J. M. Laza, E. Aranzabe, J. L. Vilas, Effect of different types of electrospun polyamide 6 nanofibres on the mechanical properties of carbon fibre/epoxy composites, Polymers 10 (11). doi:10.3390/polym10111190. 


\section{List of Figures}

$12 \times 2 \mathrm{~mm}$ (width and thickness) matchsticks cut from $\mathrm{LTHIN}_{G_{\mathrm{IC}}}, \mathrm{LV}_{G_{\mathrm{IC}}}$ and $\mathrm{LV} 2_{G_{\mathrm{IC}}}$ double cantilever beam (DCB) specimens. The circle indicates the location of the fracture process zone (FPZ) . . . . . . . .

2 Colour legend of the post-processed X-ray tomography $(\mu \mathrm{CT})$ images. NCF means non-crimp fabric. (For interpretation of the references to colour in this figure legend, the reader is referred to the web version of this article). . . . . . . . . . . . . . . . . .

$3 \mathrm{XY}$ views of the resin pockets inherent to $\left(0^{\circ} / \pm 45^{\circ}\right) \mathrm{C}-\mathrm{PLY}{ }^{\mathrm{TM}} \mathrm{NCFs}$ (refer to the coordinate system defined in Fig. 1). . . . . . . . . . .

$4 \mu \mathrm{CT}$ cross-section depicting the microstructure of $\mathrm{LTHIN}_{\mathrm{IP}}$. . . . . . .

$5 \quad \mu \mathrm{CT}$ cross-section depicting the microstructure of $\mathrm{LV} 1_{\mathrm{IP}} \cdot \mathrm{V}_{1}$ fibres are coloured purple. Debondings between $\mathrm{V}_{1}$ fibres and resin are coloured black. (For interpretation of the references to colour in this figure legend, the reader is referred to the web version of this article). . . . . . . .

$6 \quad \mathrm{~V}_{1}$ fibre observed with a synchrotron $\mathrm{X}$-ray source. (For interpretation of the references to colour in this figure legend, the reader is referred to the web version of this article).

$7 \mu \mathrm{CT}$ cross-section depicting the microstructure of $\mathrm{LV} 2_{\mathrm{IP}} \cdot \mathrm{V}_{2}$ fibres are coloured red: a) is the accumulation of $V_{2}$ fibres, b) is the single $V_{2}$ fibre. Stitching yarn fibres are coloured green. (For interpretation of the references to colour in this figure legend, the reader is referred to the web version of this article). . . . . . . . . . . . . . .

8 XY cross-sections depicting the microstructure of LV2 $2_{\mathrm{IP}}$ : a) are the $\mathrm{V}_{2}$ fibres laying close to a carbon tow $\mathrm{b}$ ) are the $\mathrm{V}_{2}$ fibres laying in a resin rich area. Debonding between stitching yarn fibres and resin is coloured black. (For interpretation of the references to colour in this figure legend, the reader is referred to the web version of this article). . . . . . . .

9 Tensile and compressive properties of LTHIN ${ }_{I P}, L V 1_{I P}$ and $L V 2_{I P}$. . . .

10 Force response and average R-curves of the $\mathrm{LTHIN}_{G_{\mathrm{IC}}}, \mathrm{LV} 1_{G_{\mathrm{IC}}}$ and $\mathrm{LV} 2_{G_{\text {IC }}}$ DCB specimens. The shaded area illustrates the standard deviation between the tests. (For interpretation of the references to colour in this figure legend, the reader is referred to the web version of this article). .

11 Mode-I initiation $\left(G_{\text {Iinit }}\right)$ and propagation $\left(G_{\text {Iprop }}\right)$ interlaminar fracture toughness of $\operatorname{LTHIN}_{G_{\mathrm{IC}}}, \mathrm{LV}_{G_{\mathrm{IC}}}$ and $\mathrm{LV}_{G_{\mathrm{IC}}} \ldots \ldots \ldots . . . . .$.

$12 \mu \mathrm{CT}$ cross-sections depicting the FPZ of the $\operatorname{LTHIN}_{G_{\mathrm{IC}}}, \mathrm{LV}_{G_{\mathrm{IC}}}$ and $\mathrm{LV} 2_{G_{\text {IC }}}$ DCB specimens. The mode-I crack (coloured black) grows towards the reader. (For interpretation of the references to colour in this figure legend, the reader is referred to the web version of this article). . 
13 Interaction between the mode-I crack of LTHIN $_{G_{\mathrm{IC}}}$ and the stitching yarn fibres. The mode-I crack (coloured black) grows towards the reader. (For interpretation of the references to colour in this figure legend, the reader is referred to the web version of this article). . . . . . . . . .

A.1 $\mu \mathrm{CT}$ cross-section depicting the microstructure of $\mathrm{LV} 1_{\mathrm{IP}}$. Despite the low-contrast of $\mathrm{V}_{1}$ fibres, their geometry can be deduced from the unequivocal shape of the debondings (in black). . . . . . . . . . .

A.2 $\mu \mathrm{CT}$ cross-section depicting the microstructure of $\mathrm{LV} 2_{\mathrm{IP}}$. . . . . . . . .

A.3 XY cross-sections depicting the microstructure of LV2 $\mathrm{IP}$ : a) are the $\mathrm{V}_{2}$ fibres laying close to a carbon tow b) are the $\mathrm{V}_{2}$ fibres laying in a resin rich area. . . . . . . . . . . . . . . . . .

A.4 $\mu \mathrm{CT}$ cross-sections depicting the FPZ of the $\mathrm{LTHIN}_{G_{\mathrm{IC}}}, \mathrm{LV} 1_{G_{\mathrm{IC}}}$ and $\mathrm{LV} 2_{G_{\mathrm{IC}}}$ DCB specimens. The mode-I crack (in black) grows towards the reader. . . . . . . . . . . . . . . . . . .

A.5 Interaction between the mode-I crack of LTHIN $_{G_{I C}}$ and the stitching yarn fibres. The mode-I crack (in black) grows towards the reader. . . . . . . 


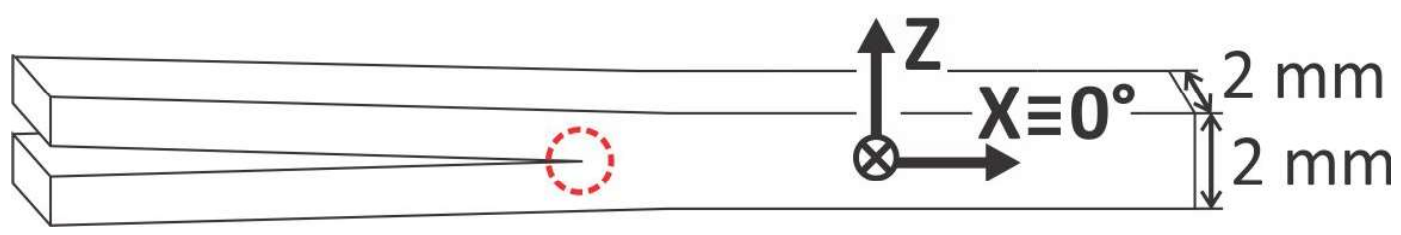

Figure 1: $2 \times 2 \mathrm{~mm}$ (width and thickness) matchsticks cut from $\mathrm{LTHIN}_{G_{\mathrm{IC}}}, \mathrm{LV} 1_{G_{\mathrm{IC}}}$ and $\mathrm{LV} 2_{G_{\mathrm{IC}}}$ double cantilever beam (DCB) specimens. The circle indicates the location of the fracture process zone (FPZ).

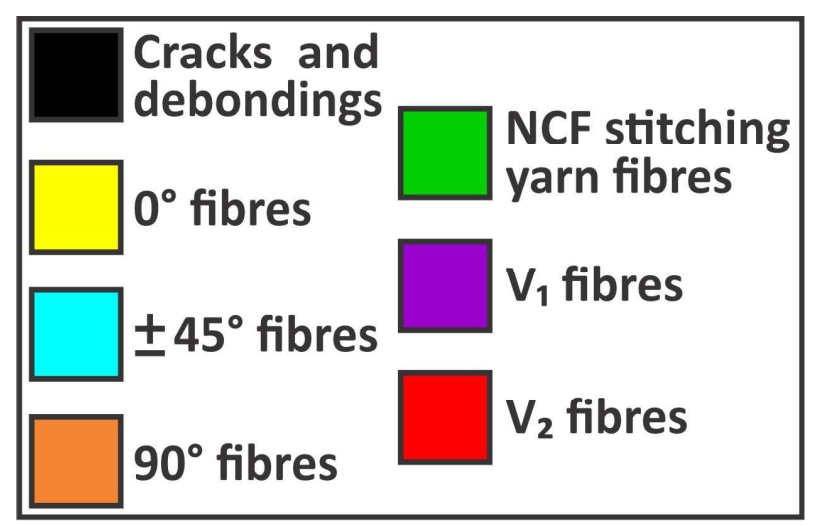

Figure 2: Colour legend of the post-processed X-ray tomography $(\mu \mathrm{CT})$ images. NCF means noncrimp fabric. (For interpretation of the references to colour in this figure legend, the reader is referred to the web version of this article). 


\section{FIGURES}

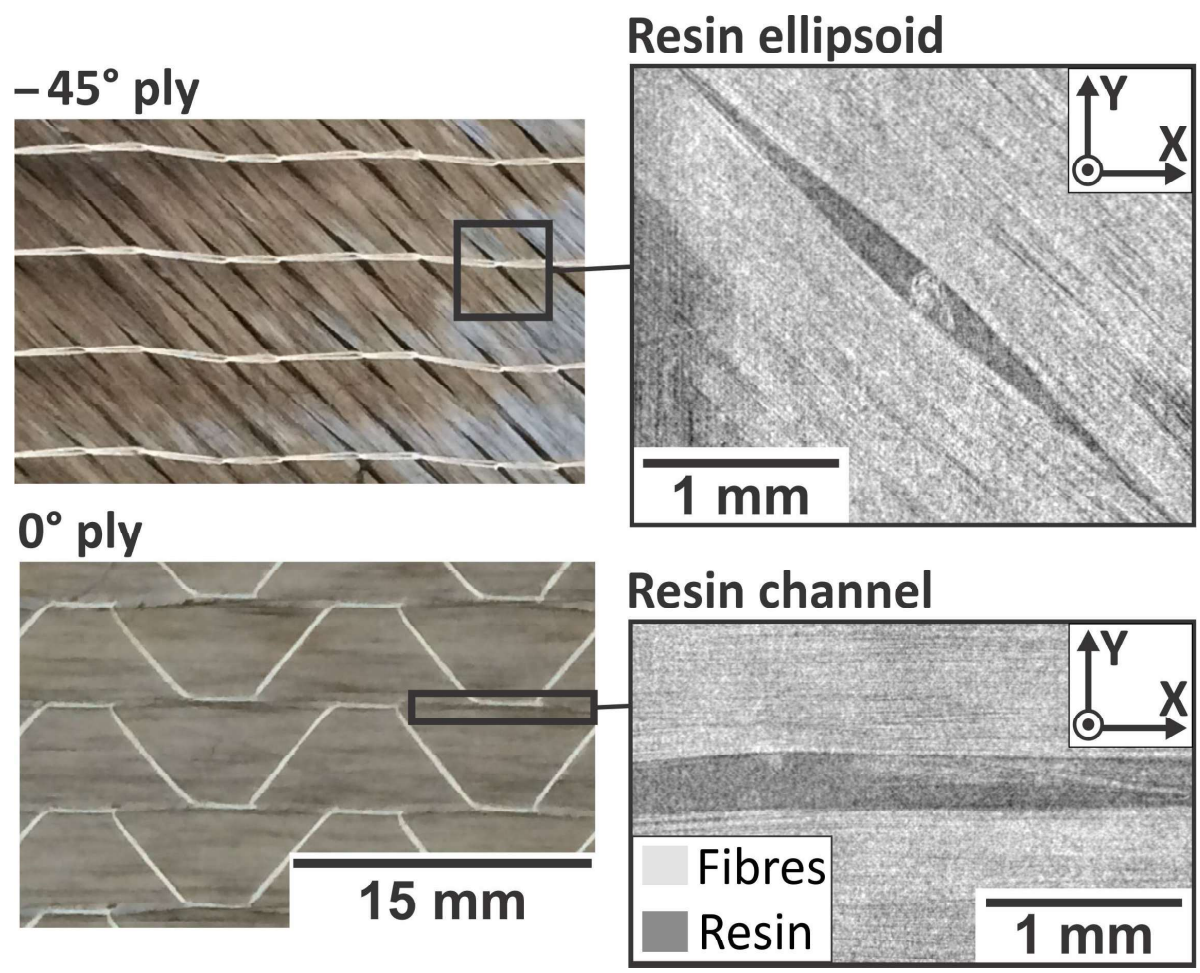

Figure 3: XY views of the resin pockets inherent to $\left(0^{\circ} / \pm 45^{\circ}\right)$ C-PLY ${ }^{\mathrm{TM}}$ NCFs (refer to the coordinate system defined in Fig. 1).

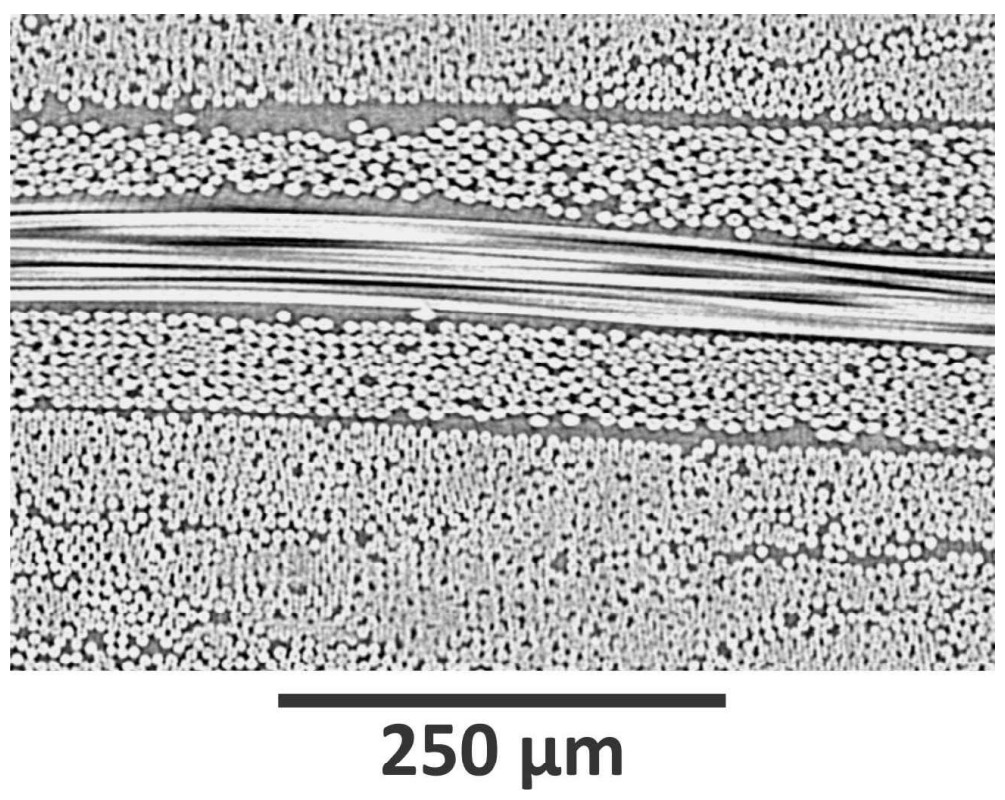

Figure 4: $\mu \mathrm{CT}$ cross-section depicting the microstructure of LTHIN $\mathrm{IP}_{\mathrm{IP}}$. 
FIGURES

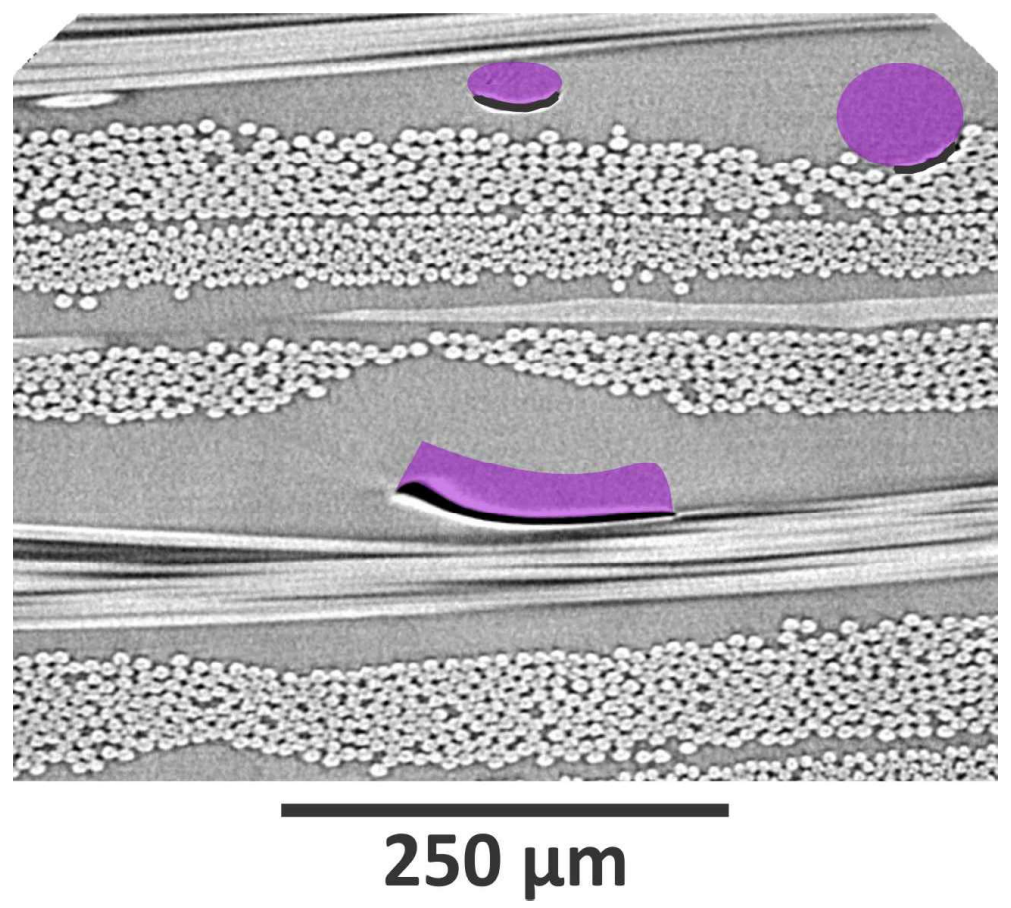

Figure 5: $\mu \mathrm{CT}$ cross-section depicting the microstructure of $\mathrm{LV} 1_{\mathrm{IP}} . \mathrm{V}_{1}$ fibres are coloured purple. Debondings between $\mathrm{V}_{1}$ fibres and resin are coloured black. (For interpretation of the references to colour in this figure legend, the reader is referred to the web version of this article).

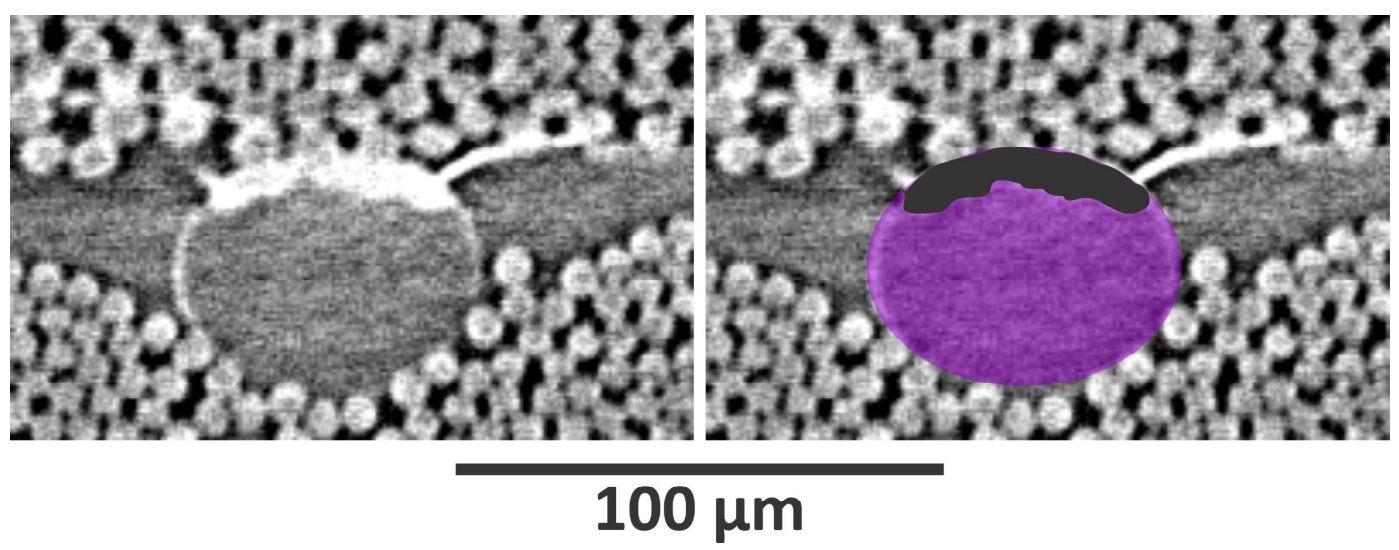

Figure 6: $\mathrm{V}_{1}$ fibre observed with a synchrotron $\mathrm{X}$-ray source. (For interpretation of the references to colour in this figure legend, the reader is referred to the web version of this article). 
FIGURES

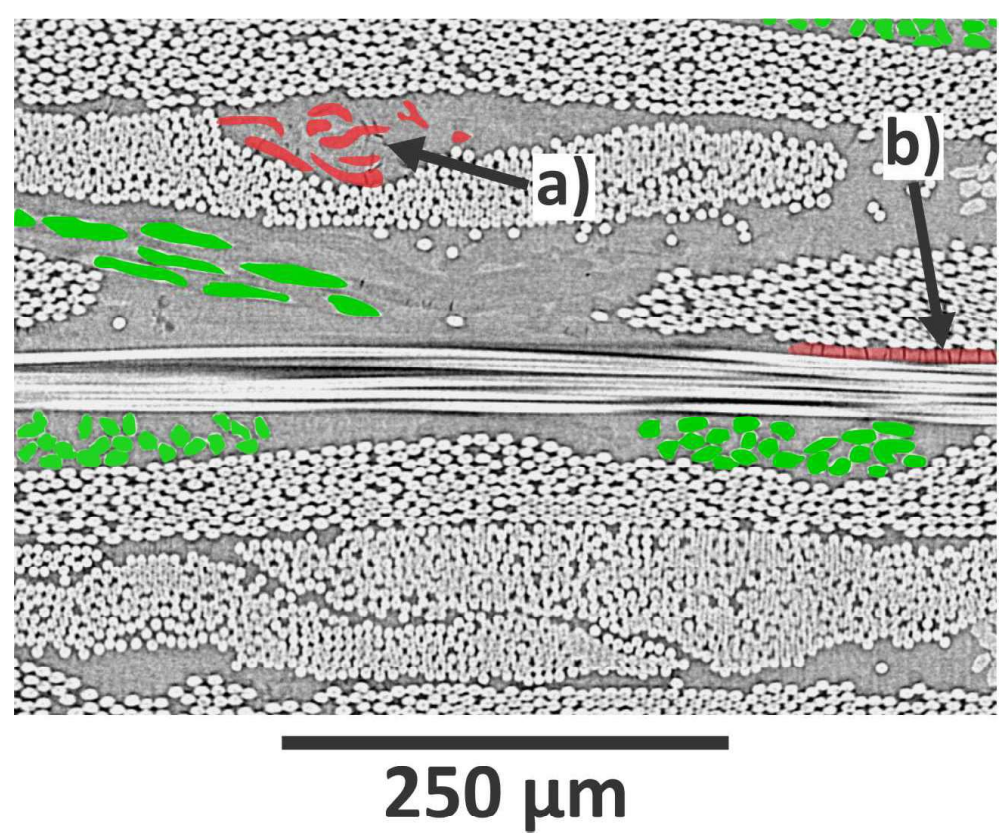

Figure 7: $\mu \mathrm{CT}$ cross-section depicting the microstructure of $\mathrm{LV} 2_{\mathrm{IP}} \cdot \mathrm{V}_{2}$ fibres are coloured red: a) is the accumulation of $\mathrm{V}_{2}$ fibres, $\mathrm{b}$ ) is the single $\mathrm{V}_{2}$ fibre. Stitching yarn fibres are coloured green. (For interpretation of the references to colour in this figure legend, the reader is referred to the web version of this article).

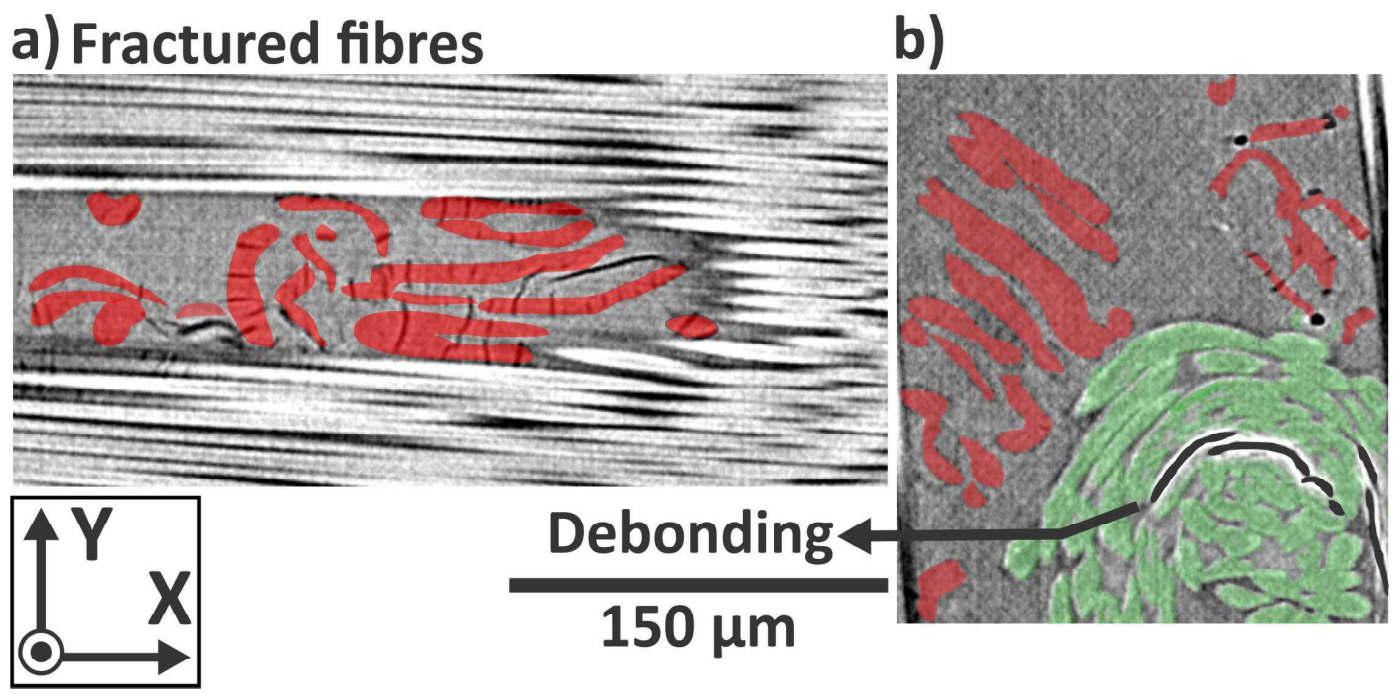

Figure 8: XY cross-sections depicting the microstructure of LV2 $\mathrm{IP}$ : a) are the $\mathrm{V}_{2}$ fibres laying close to a carbon tow $\mathrm{b}$ ) are the $\mathrm{V}_{2}$ fibres laying in a resin rich area. Debonding between stitching yarn fibres and resin is coloured black. (For interpretation of the references to colour in this figure legend, the reader is referred to the web version of this article). 
FIGURES

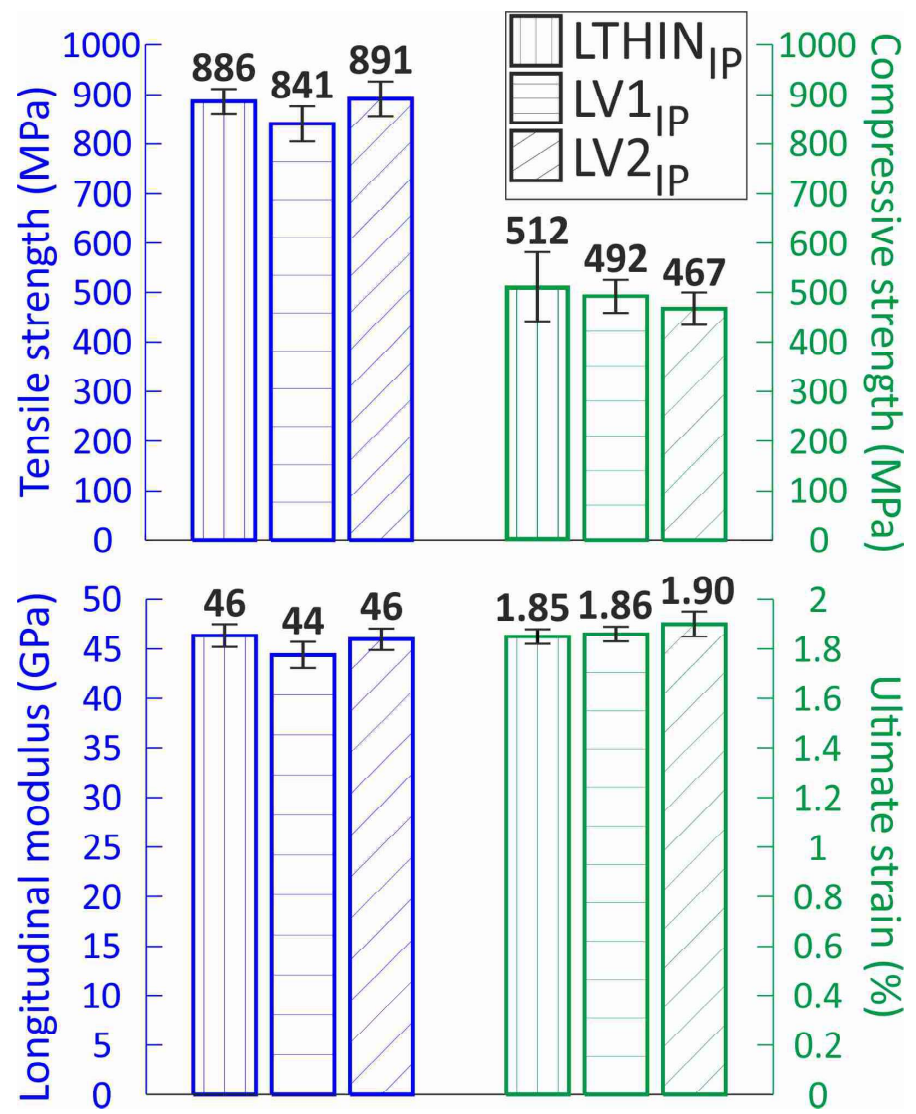

Figure 9: Tensile and compressive properties of $\mathrm{LTHIN}_{\mathrm{IP}}, \mathrm{LV} 1_{\mathrm{IP}}$ and $\mathrm{LV} 2_{\mathrm{IP}}$. 


\section{FIGURES}
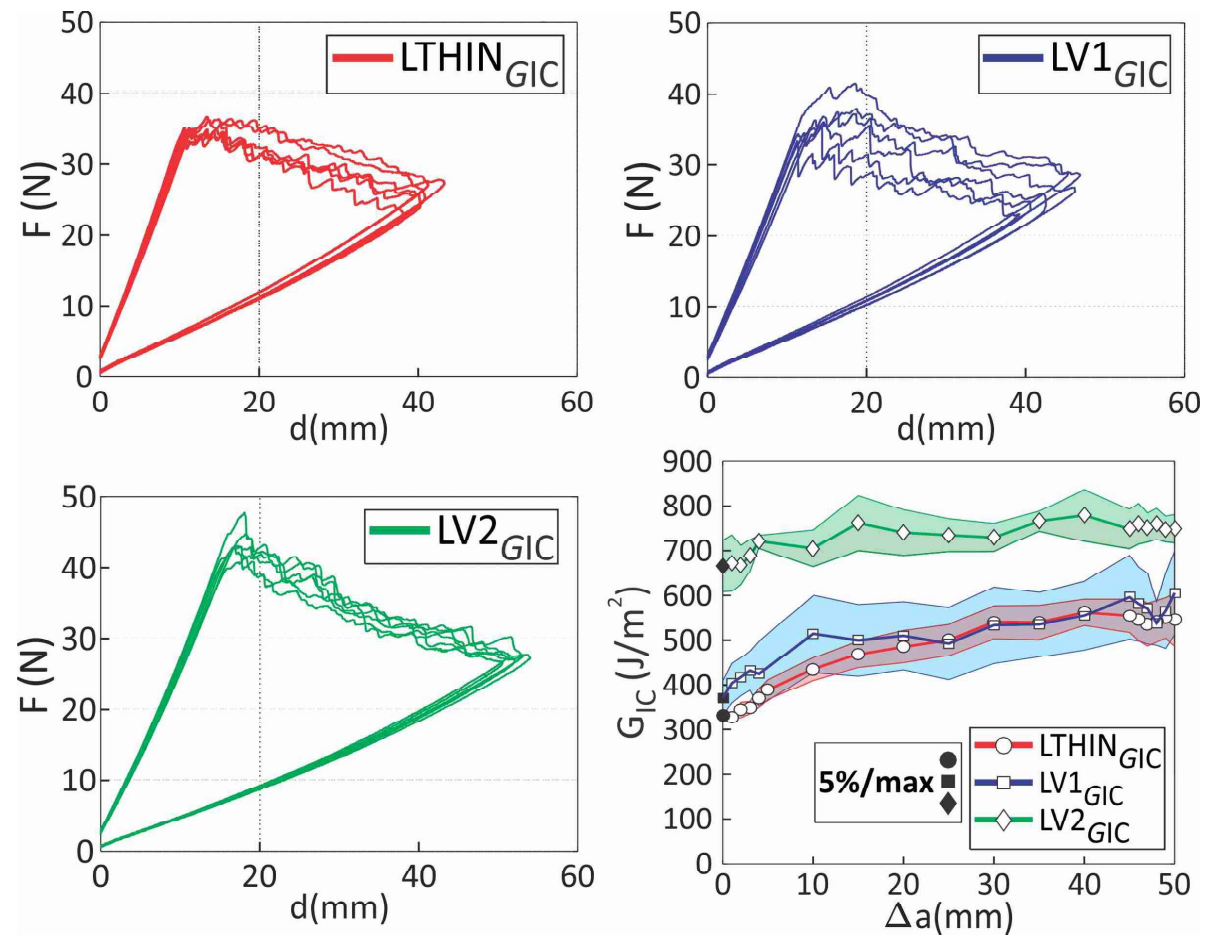

Figure 10: Force response and average R-curves of the $\mathrm{LTHIN}_{G_{\mathrm{IC}}}, \mathrm{LV} 1_{G_{\mathrm{IC}}}$ and $\mathrm{LV} 2_{G_{\mathrm{IC}}}$ DCB specimens. The shaded area illustrates the standard deviation between the tests. (For interpretation of the references to colour in this figure legend, the reader is referred to the web version of this article).

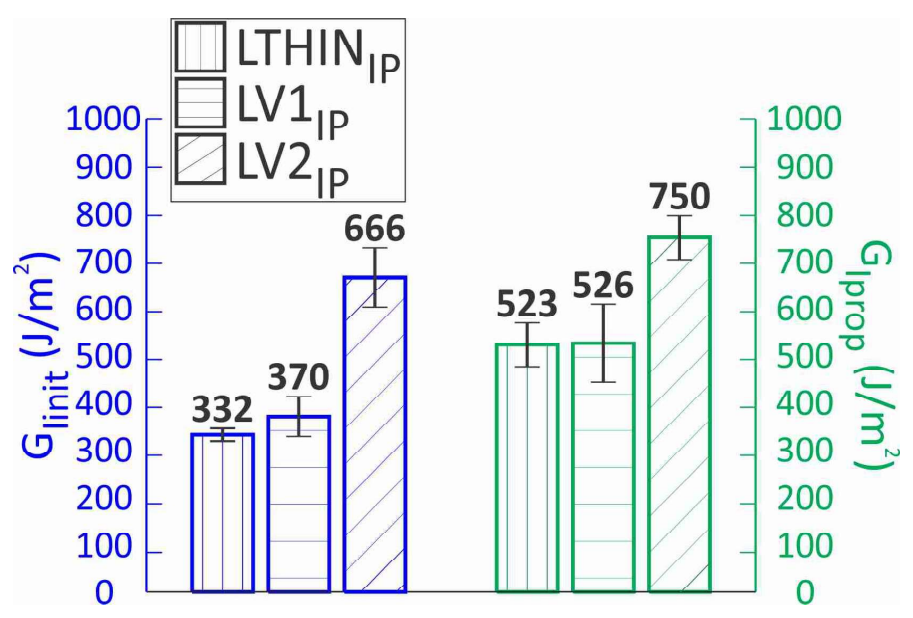

Figure 11: Mode-I initiation $\left(G_{\text {Iinit }}\right)$ and propagation $\left(G_{\text {Iprop }}\right)$ interlaminar fracture toughness of LTHIN $_{G_{\text {IC }}}, \mathrm{LV} 1_{G_{\text {IC }}}$ and LV2 $2_{G_{\mathrm{IC}}}$. 


\section{a) LTHIN $_{\text {GIC }}$}

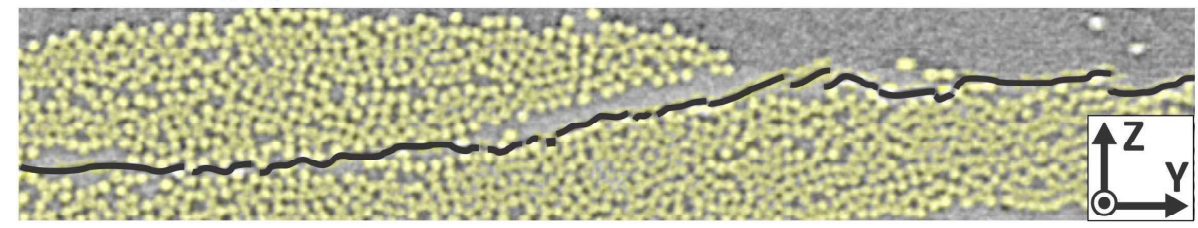

\section{b) $\mathrm{LV}_{\text {GIC }}$}

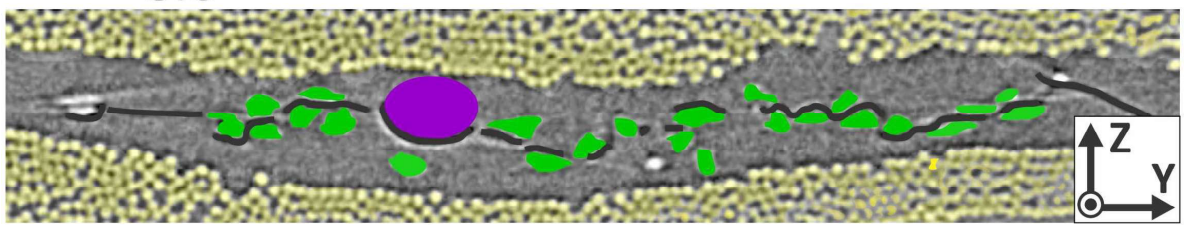

\section{c) $\mathrm{LV}_{\text {GIC }}$}

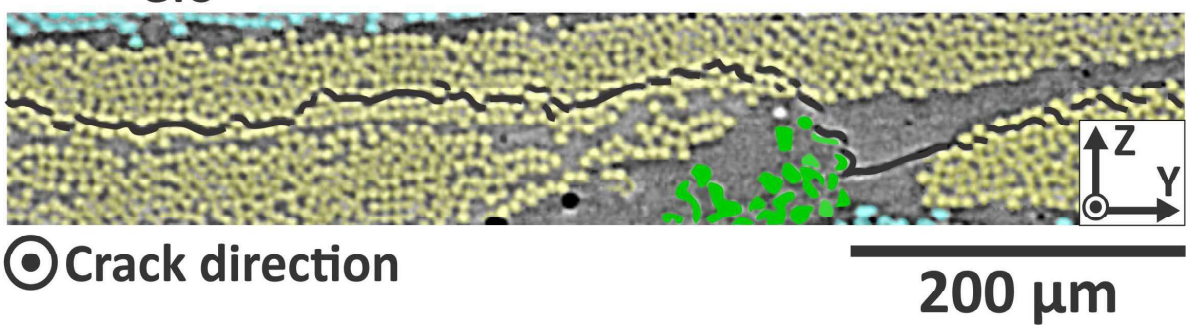

Figure 12: $\mu \mathrm{CT}$ cross-sections depicting the FPZ of the $\mathrm{LTHIN}_{G_{\mathrm{IC}}}, \mathrm{LV} 1_{G_{\mathrm{IC}}}$ and $\mathrm{LV} 2_{G_{\mathrm{IC}}}$ DCB specimens. The mode-I crack (coloured black) grows towards the reader. (For interpretation of the references to colour in this figure legend, the reader is referred to the web version of this article).

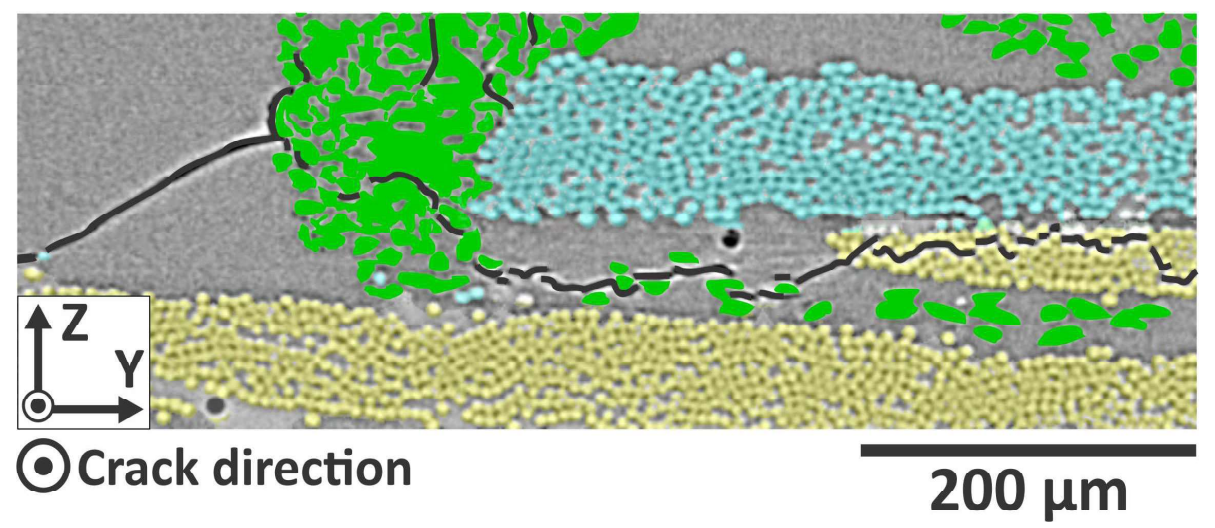

Figure 13: Interaction between the mode-I crack of LTHIN $_{G_{I C}}$ and the stitching yarn fibres. The mode-I crack (coloured black) grows towards the reader. (For interpretation of the references to colour in this figure legend, the reader is referred to the web version of this article). 


\section{FIGURES}

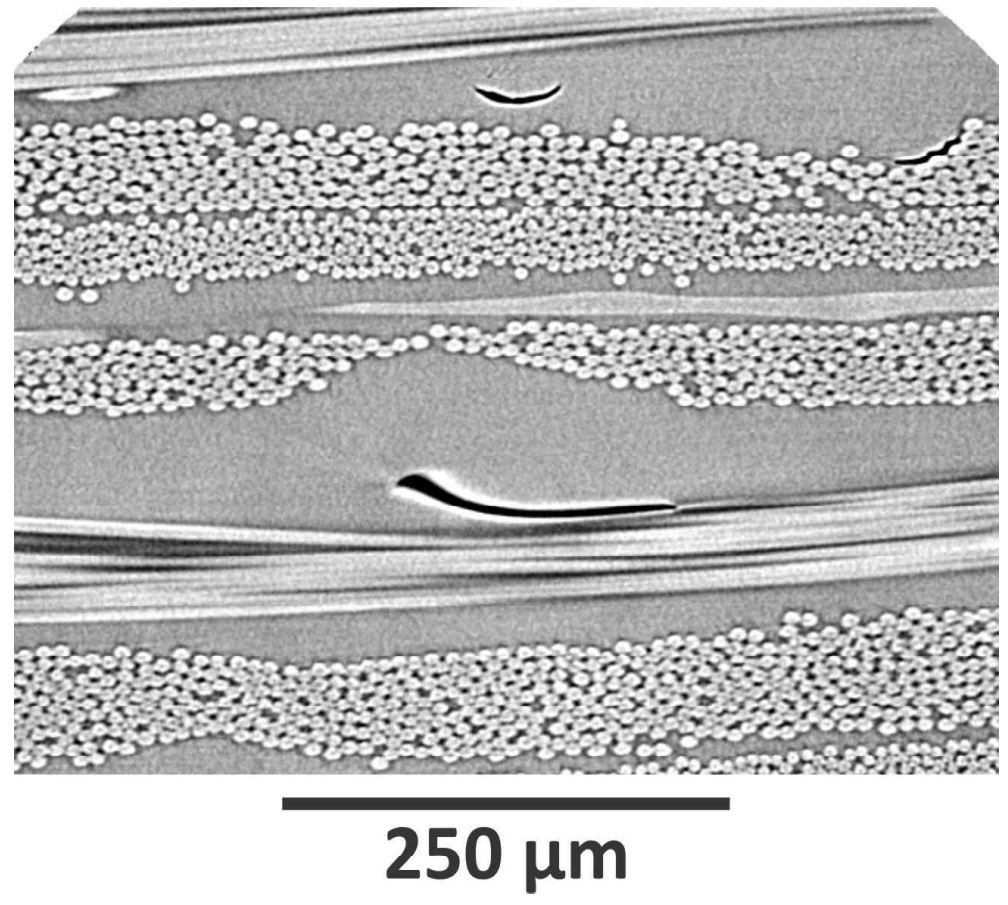

Figure A.1: $\mu \mathrm{CT}$ cross-section depicting the microstructure of $L V 1_{I P}$. Despite the low-contrast of $\mathrm{V}_{1}$ fibres, their geometry can be deduced from the unequivocal shape of the debondings (in black).

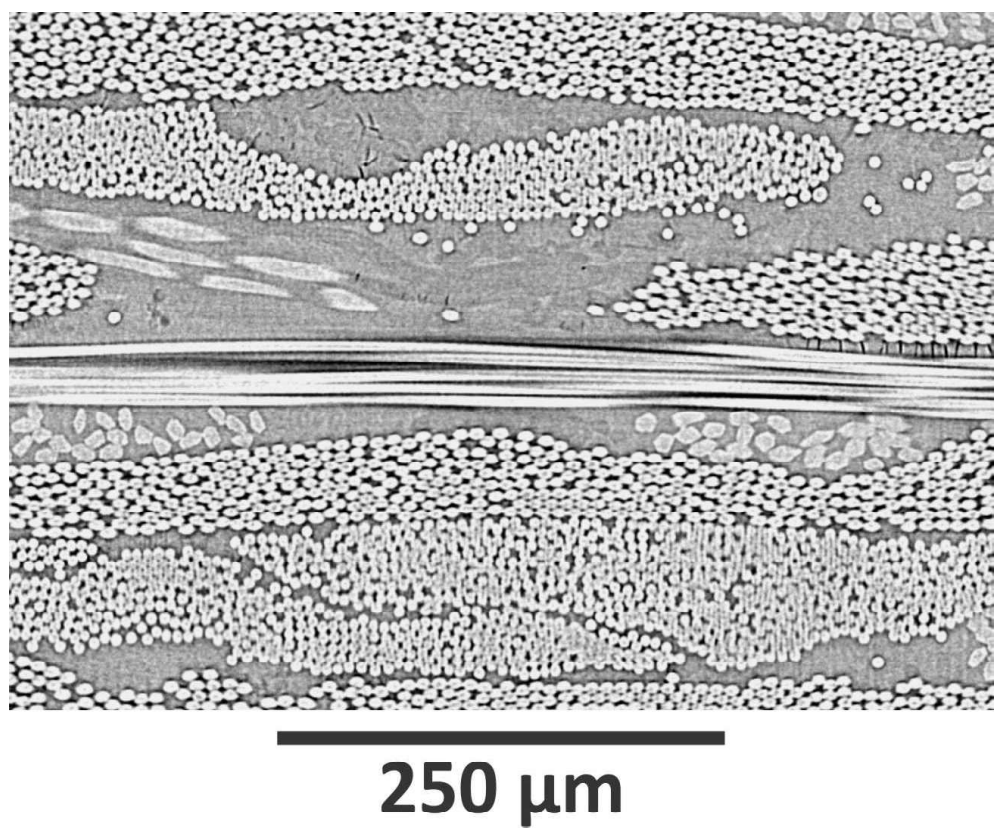

Figure A.2: $\mu \mathrm{CT}$ cross-section depicting the microstructure of LV2 $\mathrm{IP}$. 


\section{a) Fractured fibres}

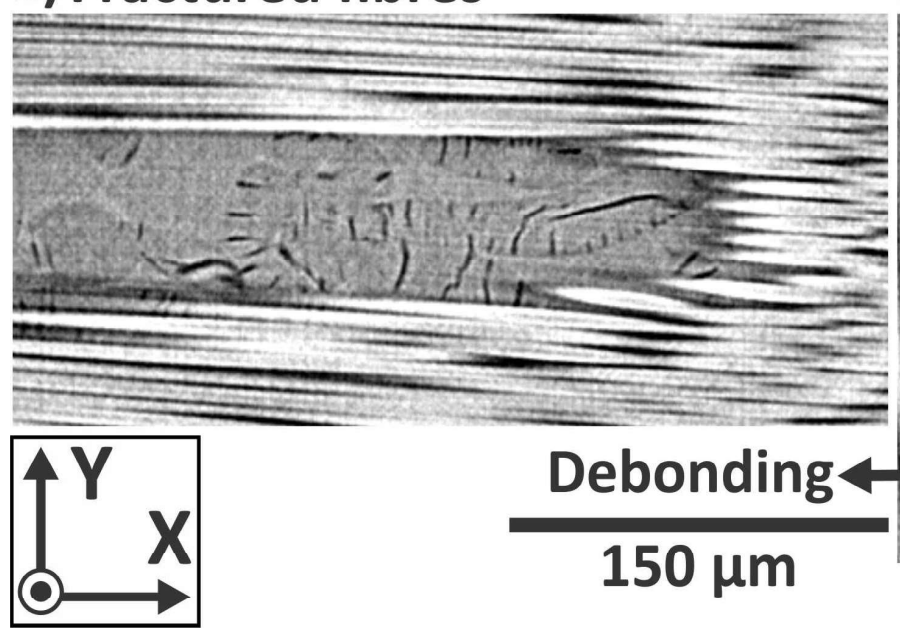

b)

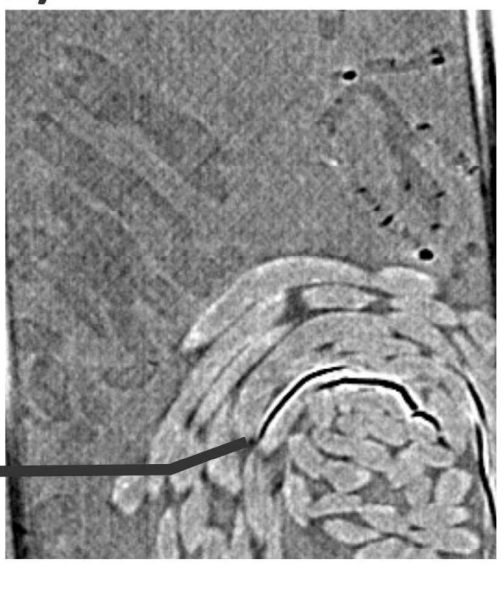

Figure A.3: XY cross-sections depicting the microstructure of $\mathrm{LV} 2_{\mathrm{IP}}$ : a) are the $\mathrm{V}_{2}$ fibres laying close to a carbon tow $\mathrm{b}$ ) are the $\mathrm{V}_{2}$ fibres laying in a resin rich area.

\section{a) LTHIN $_{G I C}$}

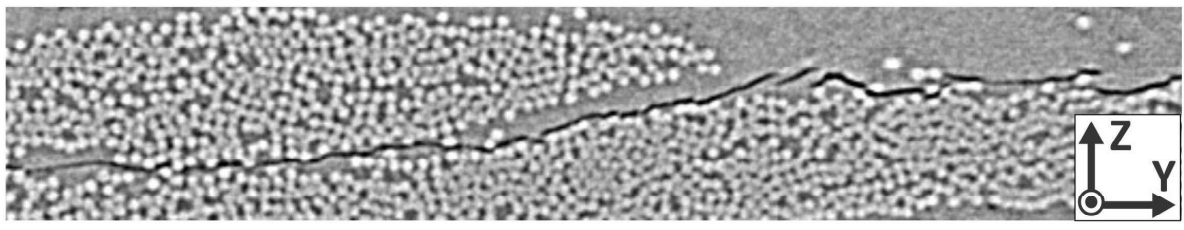

b) ${ }^{L V} 1_{G I C}$

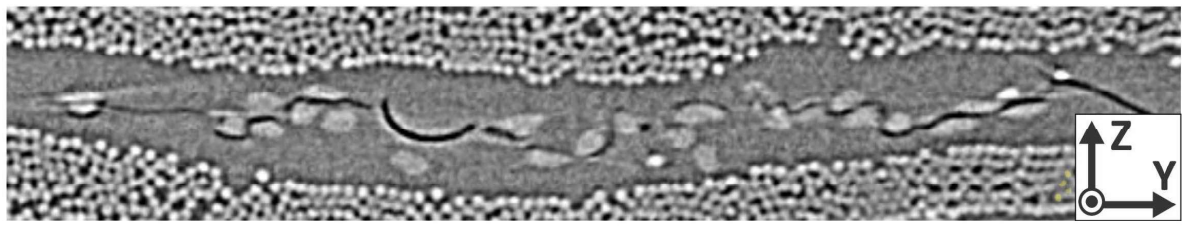

c) $\mathrm{LV}_{\text {GIC }}$

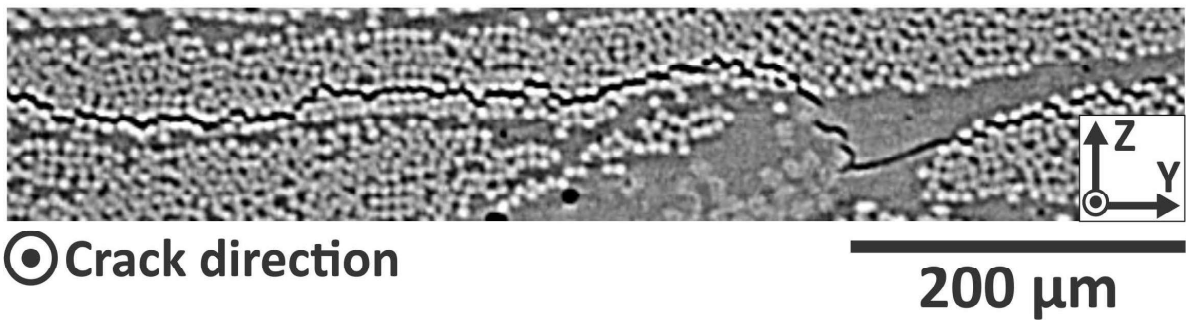

Figure A.4: $\mu \mathrm{CT}$ cross-sections depicting the FPZ of the $\mathrm{LTHIN}_{G_{\mathrm{IC}}}, \mathrm{LV} 1_{G_{\mathrm{IC}}}$ and $\mathrm{LV} 2_{G_{\mathrm{IC}}} \mathrm{DCB}$ specimens. The mode-I crack (in black) grows towards the reader. 
FIGURES

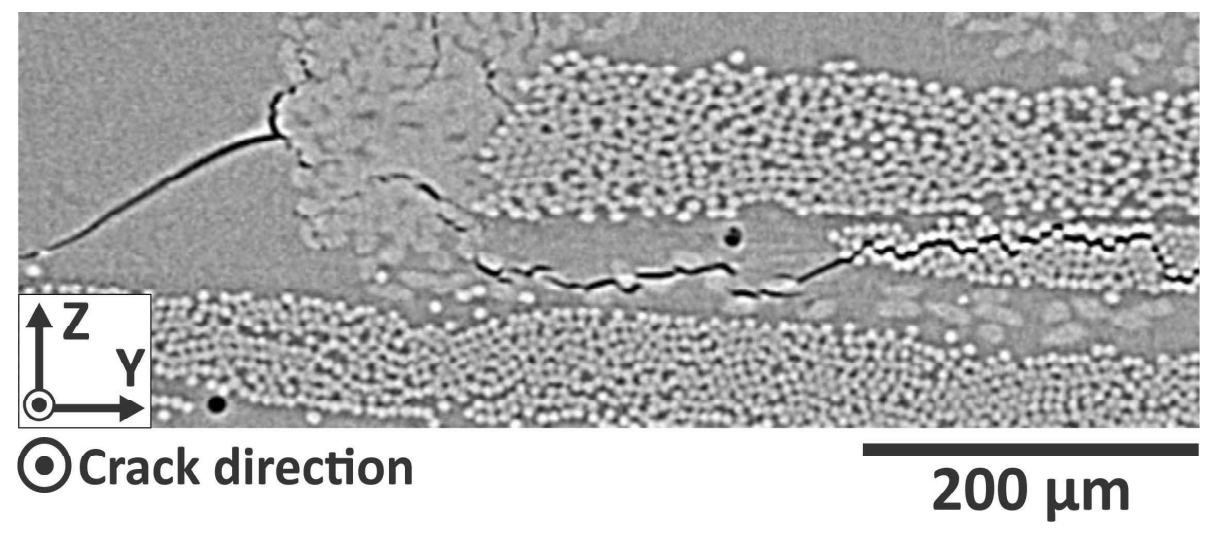

Figure A.5: Interaction between the mode-I crack of LTHIN $_{G_{\text {IC }}}$ and the stitching yarn fibres. The mode-I crack (in black) grows towards the reader. 


\section{List of Tables}

1 Laminates devised for in-plane (tension and compression) and mode-I interlaminar fracture toughness experiments. Non-crimp fabrics are indicated with parenthesis. The $\$$ sign means only one veil in the symmetry

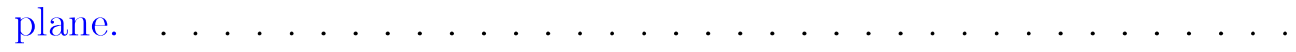


Table 1: Laminates devised for in-plane (tension and compression) and mode-I interlaminar fracture toughness experiments. Non-crimp fabrics are indicated with parenthesis. The $\$$ sign means only one veil in the symmetry plane.

\begin{tabular}{|c|c|c|}
\hline Laminate & Stacking sequence & Purpose \\
\hline LTHIN $_{\text {IP }}$ & {$\left[\left(45^{\circ} / 0^{\circ}\right) /\left(-45^{\circ} / 90^{\circ}\right)\right]_{4 s}$} & \multirow{3}{*}{ In-plane testing } \\
\hline$\overline{L V 1_{I P}}$ & {$\left[\left(45^{\circ} / \mathrm{V}_{1} / 0^{\circ}\right) / \mathrm{V}_{1} /\left(-45^{\circ} / \mathrm{V}_{1} / 90^{\circ}\right) / \mathrm{V}_{1}\right]_{4 \$}$} & \\
\hline $\mathrm{LV} 2_{\mathrm{IP}}$ & {$\left[\left(45^{\circ} / \mathrm{V}_{2} / 0^{\circ}\right) / \mathrm{V}_{2} /\left(-45^{\circ} / \mathrm{V}_{2} / 90^{\circ}\right) / \mathrm{V}_{2}\right]_{4 \$}$} & \\
\hline LTHIN $_{G_{\text {IC }}}$ & {$\left[\left(45^{\circ} / 90^{\circ}\right) /\left(-45^{\circ} / 0^{\circ}\right)\right]_{6 s}$} & \multirow{3}{*}{$\begin{array}{l}\text { Mode-I interlaminar } \\
\text { fracture toughness } \\
\text { testing }\end{array}$} \\
\hline $\mathrm{LV} 1_{G_{\mathrm{IC}}}$ & {$\left[\left(45^{\circ} / 90^{\circ}\right) /\left(-45^{\circ} / 0^{\circ}\right) / \mathrm{V}_{1}\right]_{6 \$}$} & \\
\hline $\mathrm{LV} 2_{G_{\mathrm{IC}}}$ & {$\left[\left(45^{\circ} / 90^{\circ}\right) /\left(-45^{\circ} / 0^{\circ}\right) / \mathrm{V}_{2}\right]_{6 \$}$} & \\
\hline
\end{tabular}




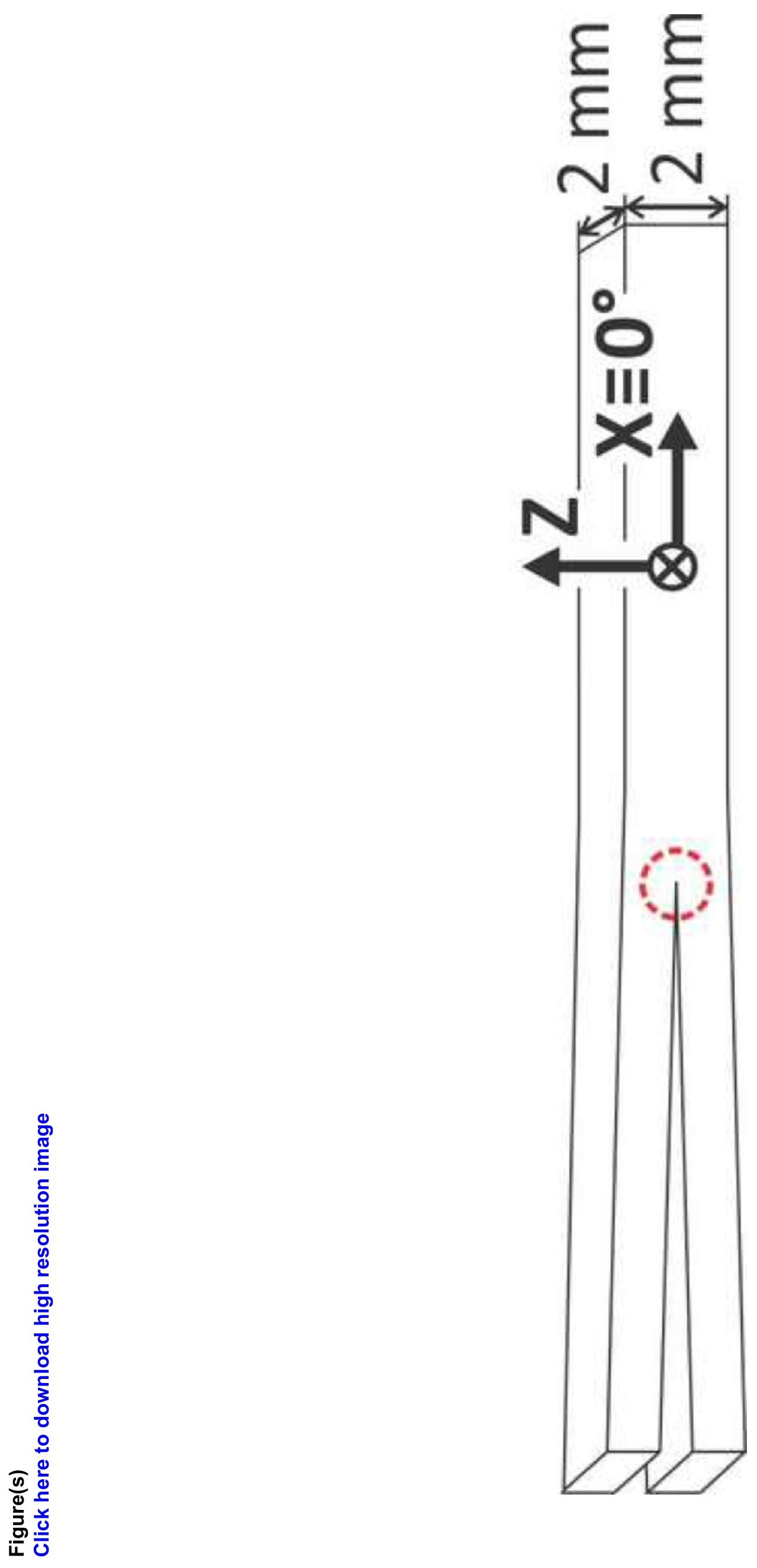



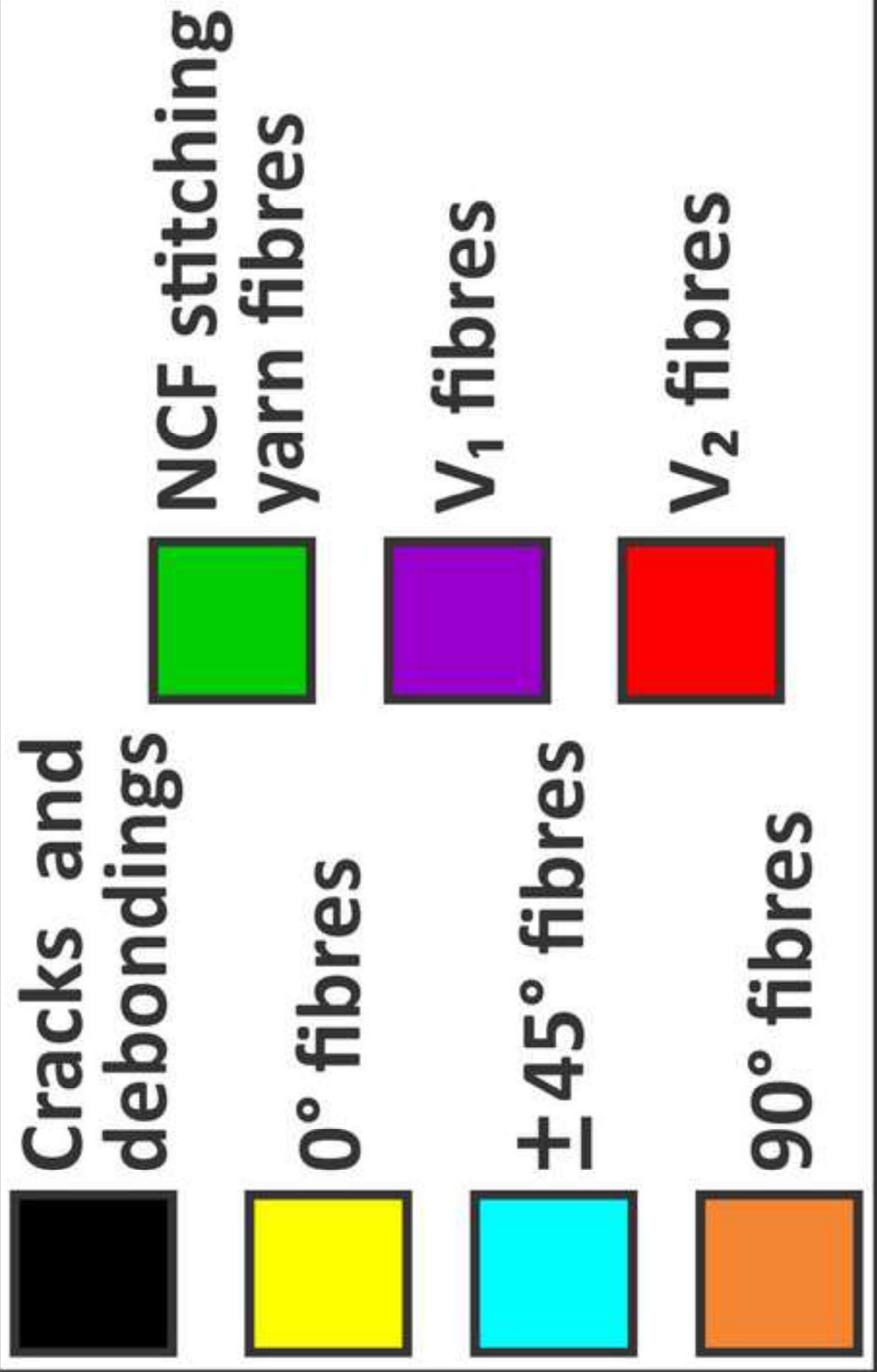


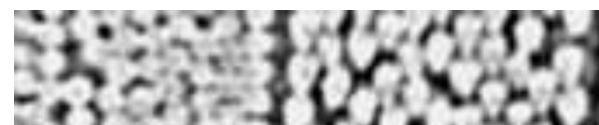

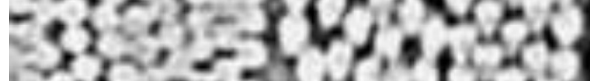
$x 3=-21$ \& $x+2 x$

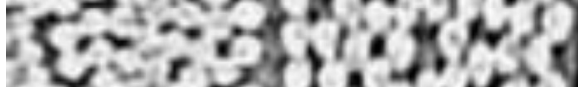

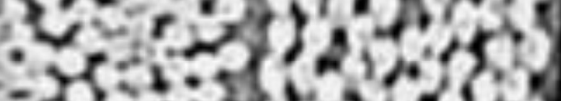
$-2=25 x+2$ $\because 20: 23(5,3)$ is. $=015(125$

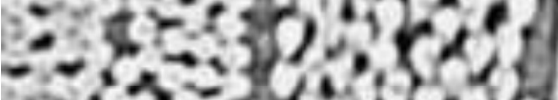
is $x=2$ iston $52 \pm 2,20$ n. 33.34 $\because x-3+x, 0$ $-2=3 x$ t. 3 s sta - $2.30 \mathrm{~s}$ $-x+35$ sides

$r=0 \times 2$ istocts $-2,10 \mathrm{c}$ a.? - e 350 Ais 30.2 ris $3 x$ द2: 3

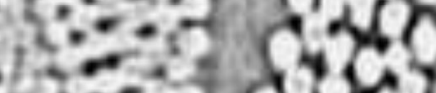
, 50 .

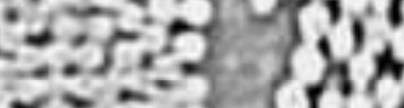
$r=-3$ s

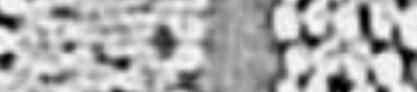

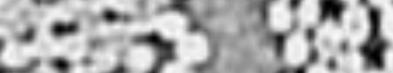
$4,21 \%$ $5=3 \cos 5$ $1=x-3$ \% 23 t - $x^{2}+30$ r.t. 5 Sot is 0 S. $=-30.0$

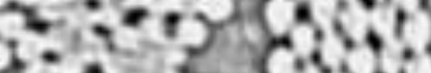
ti, 5 sint

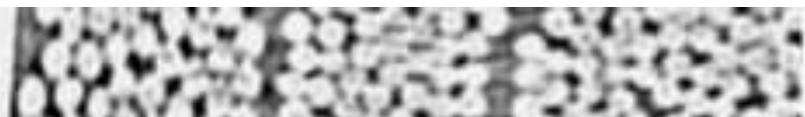

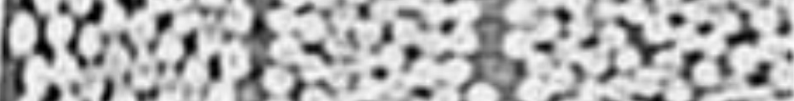

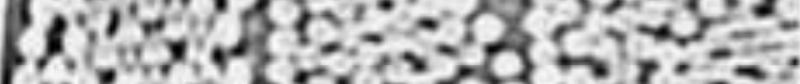

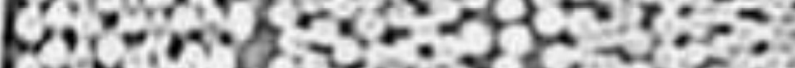

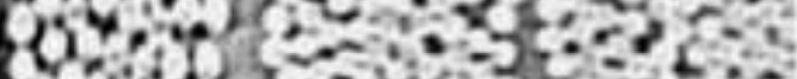

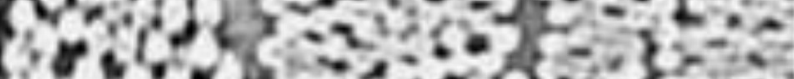

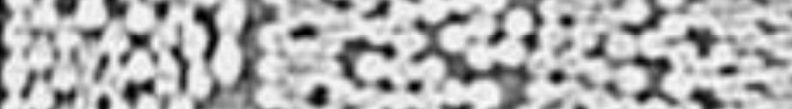

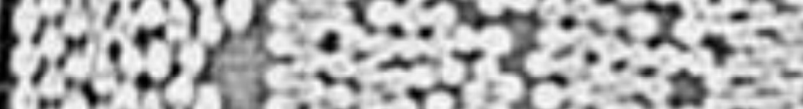

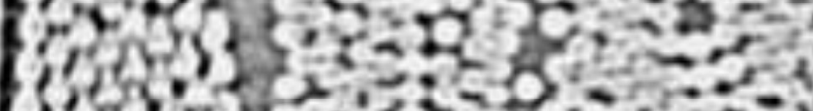

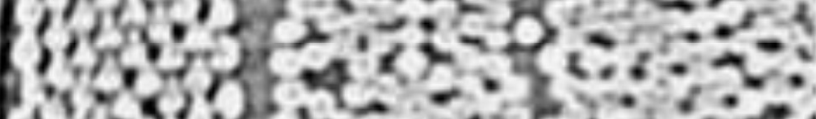

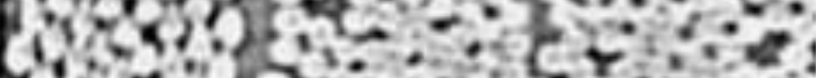

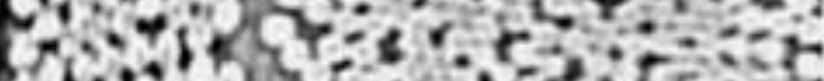

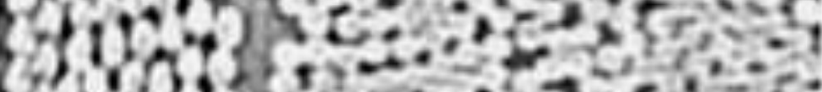
(3)

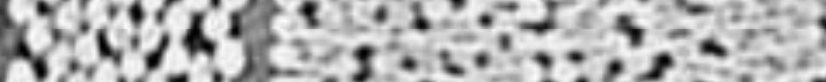

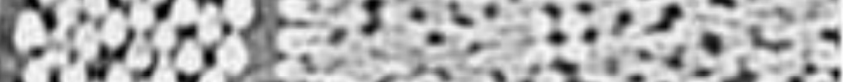

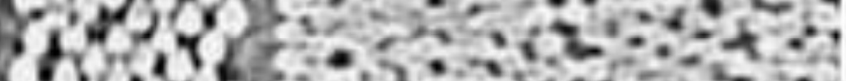

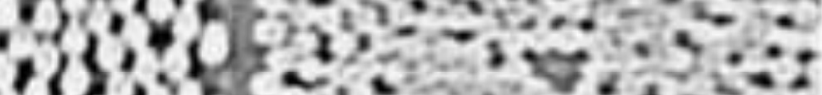

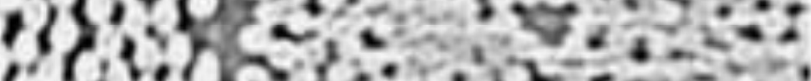

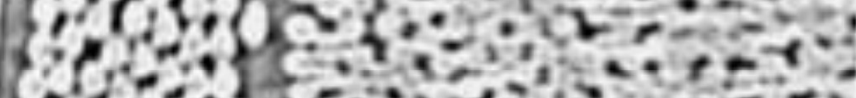

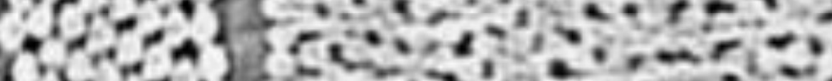

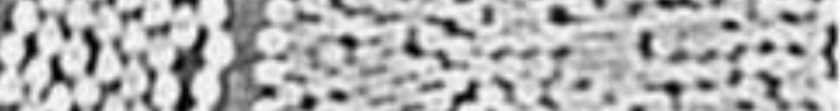

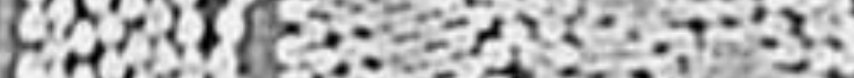

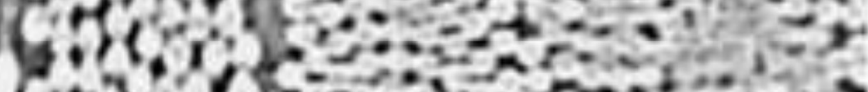

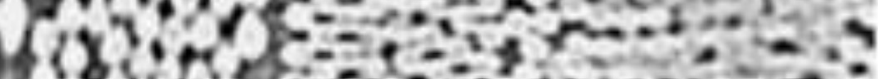

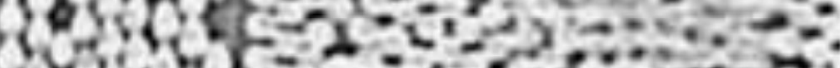
W.

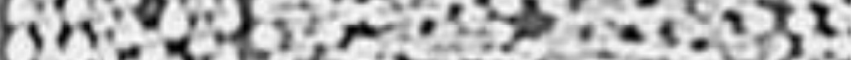

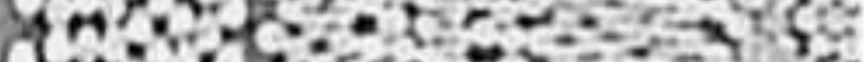

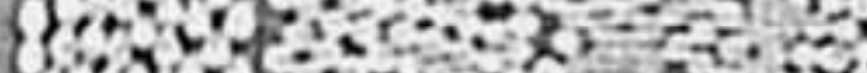

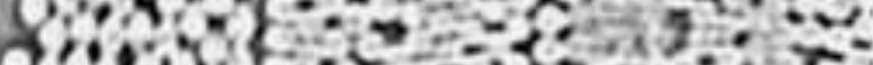

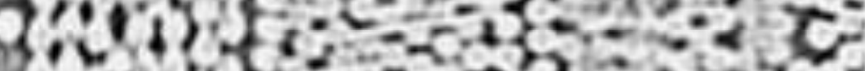
$(1,4,2),-4,2, x_{2},-2,3,5$

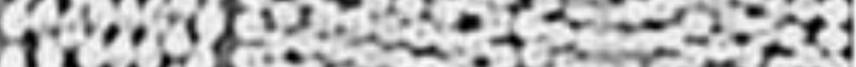

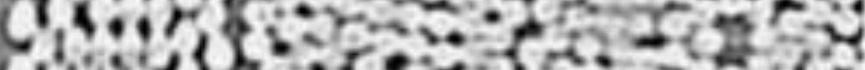

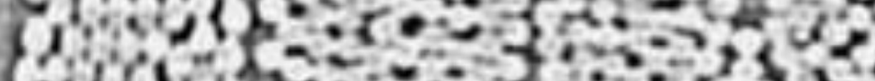

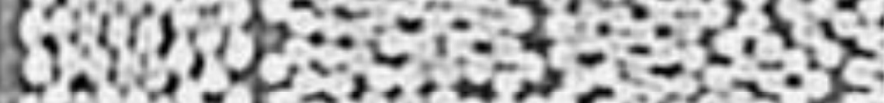

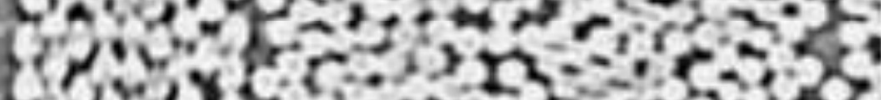

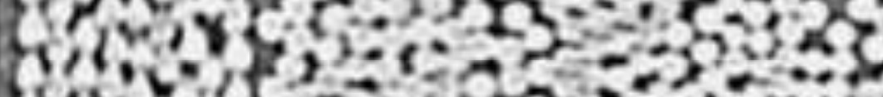

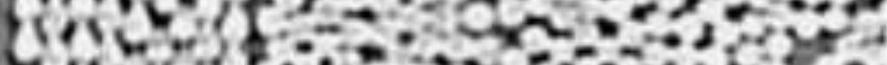

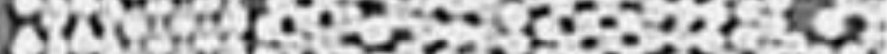

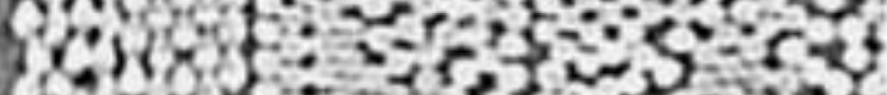

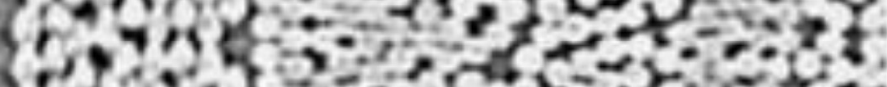

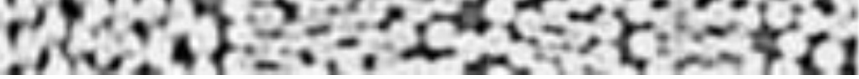




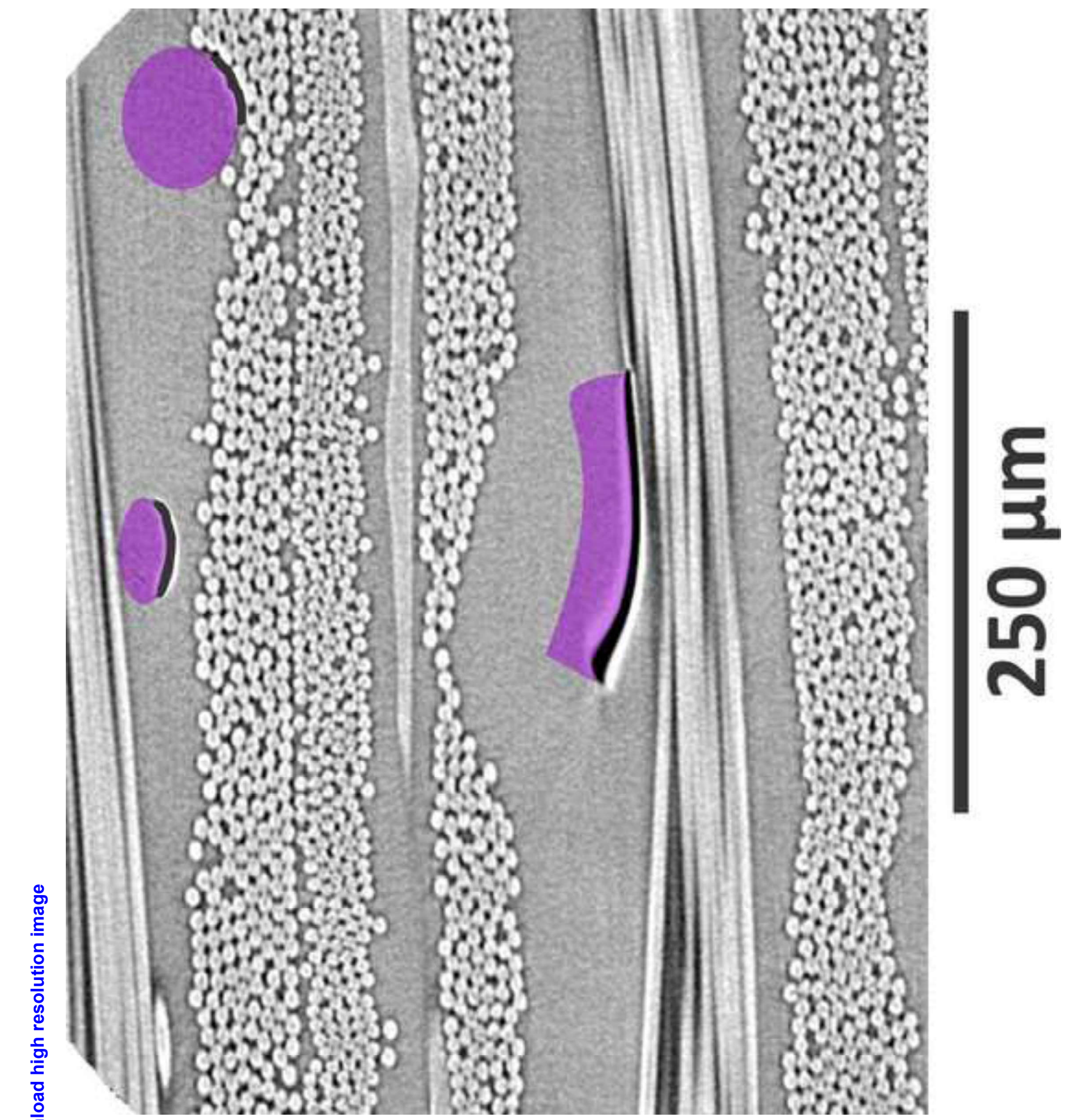



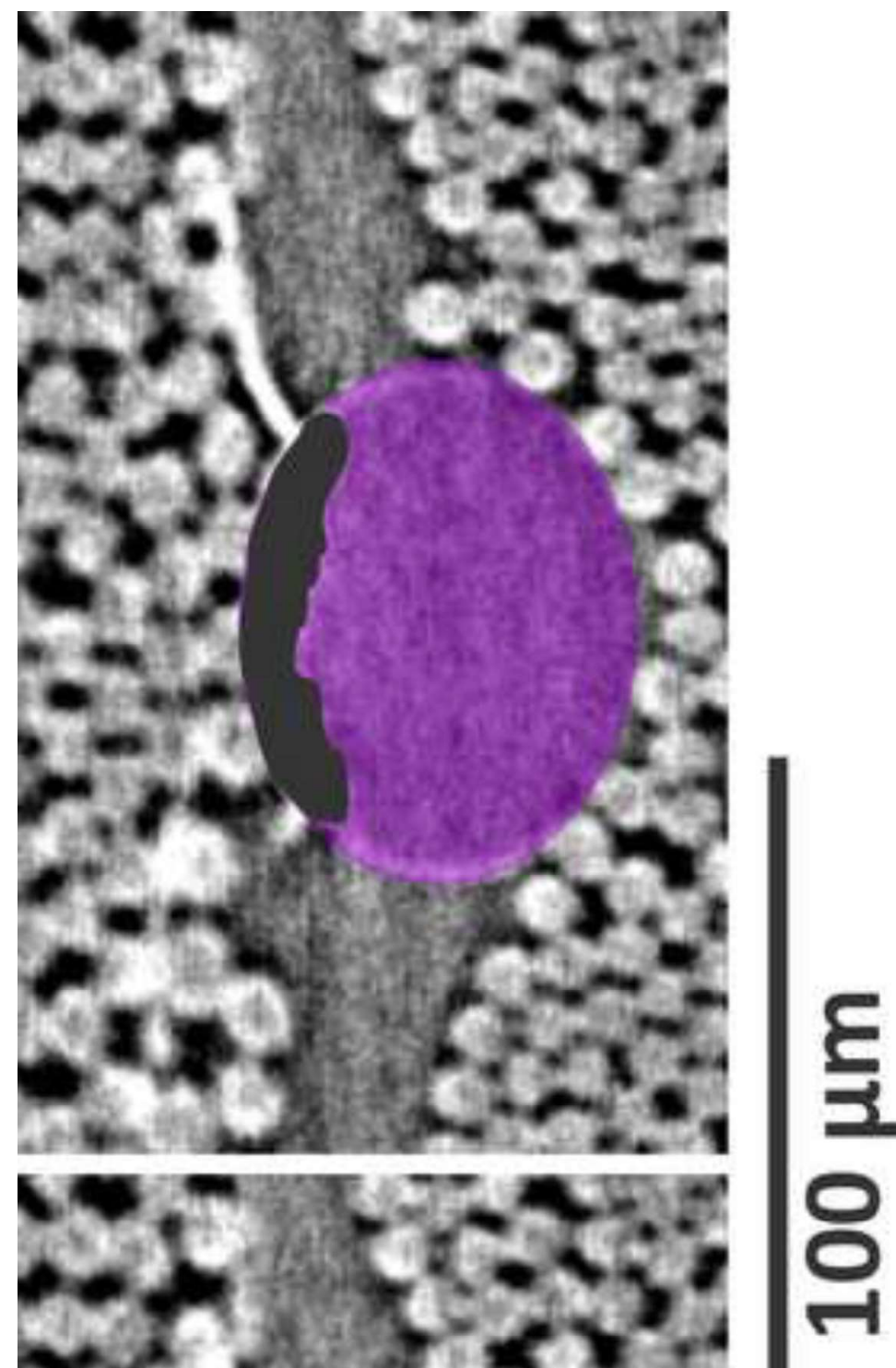

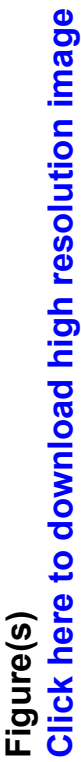




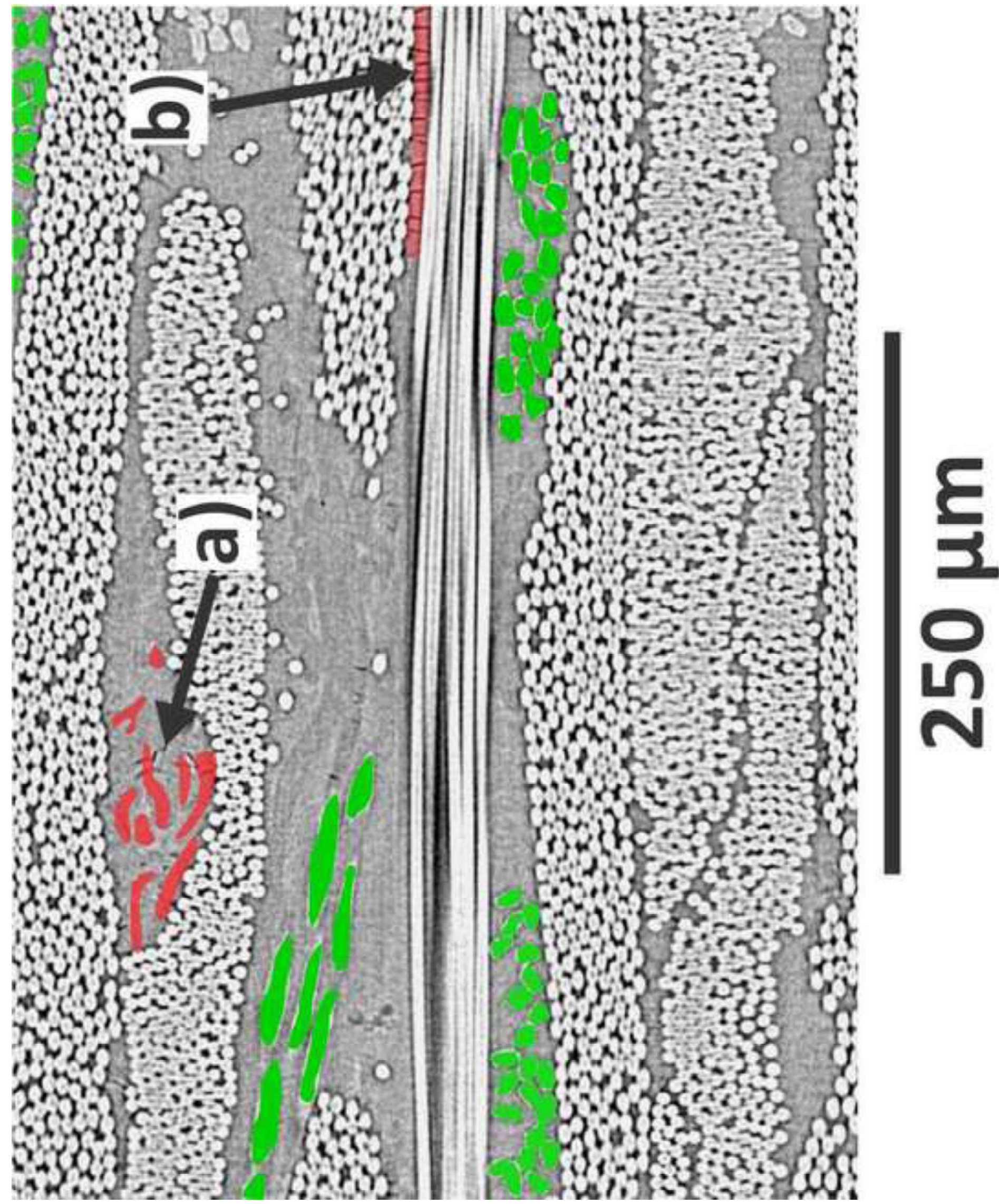




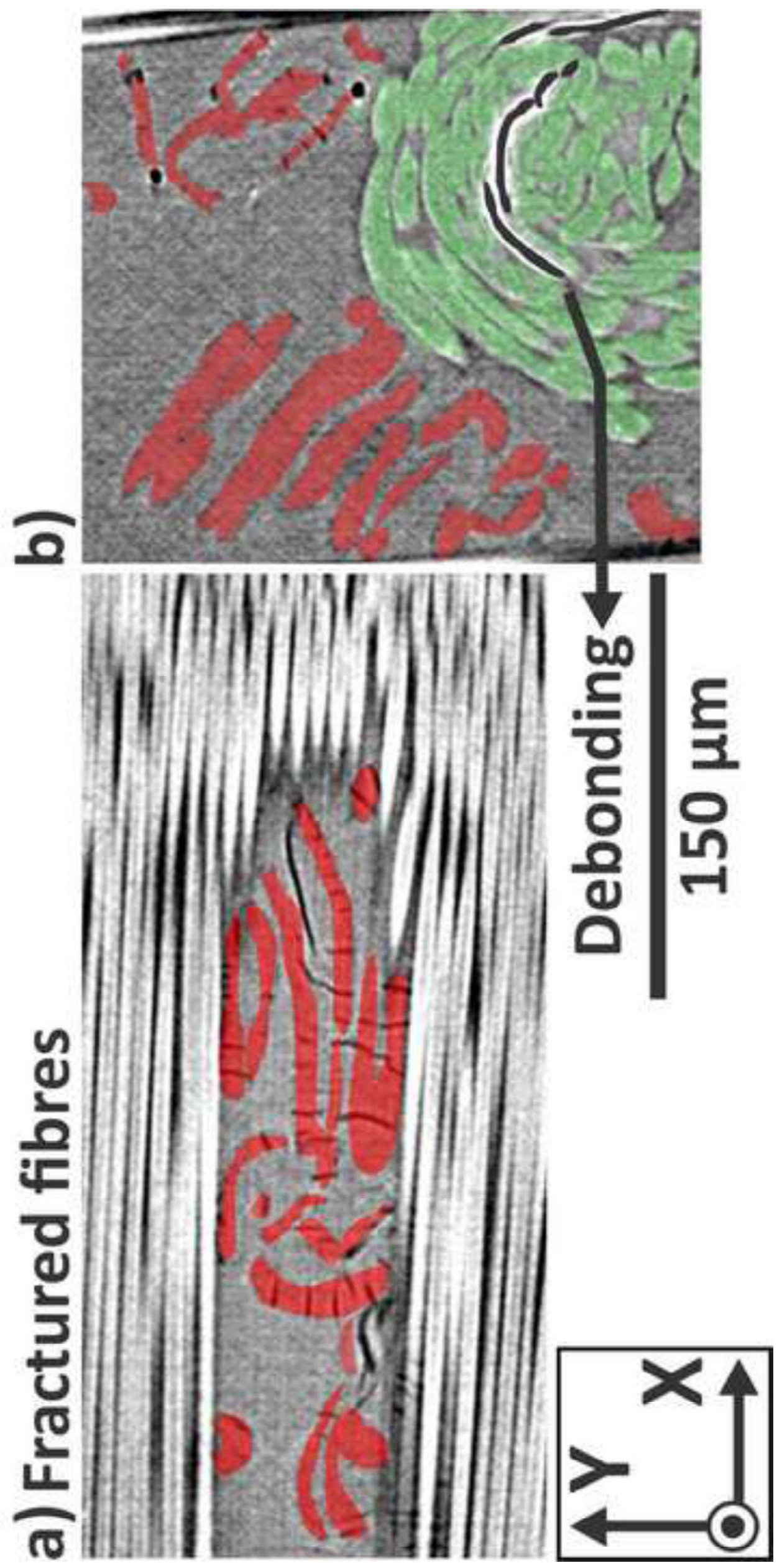



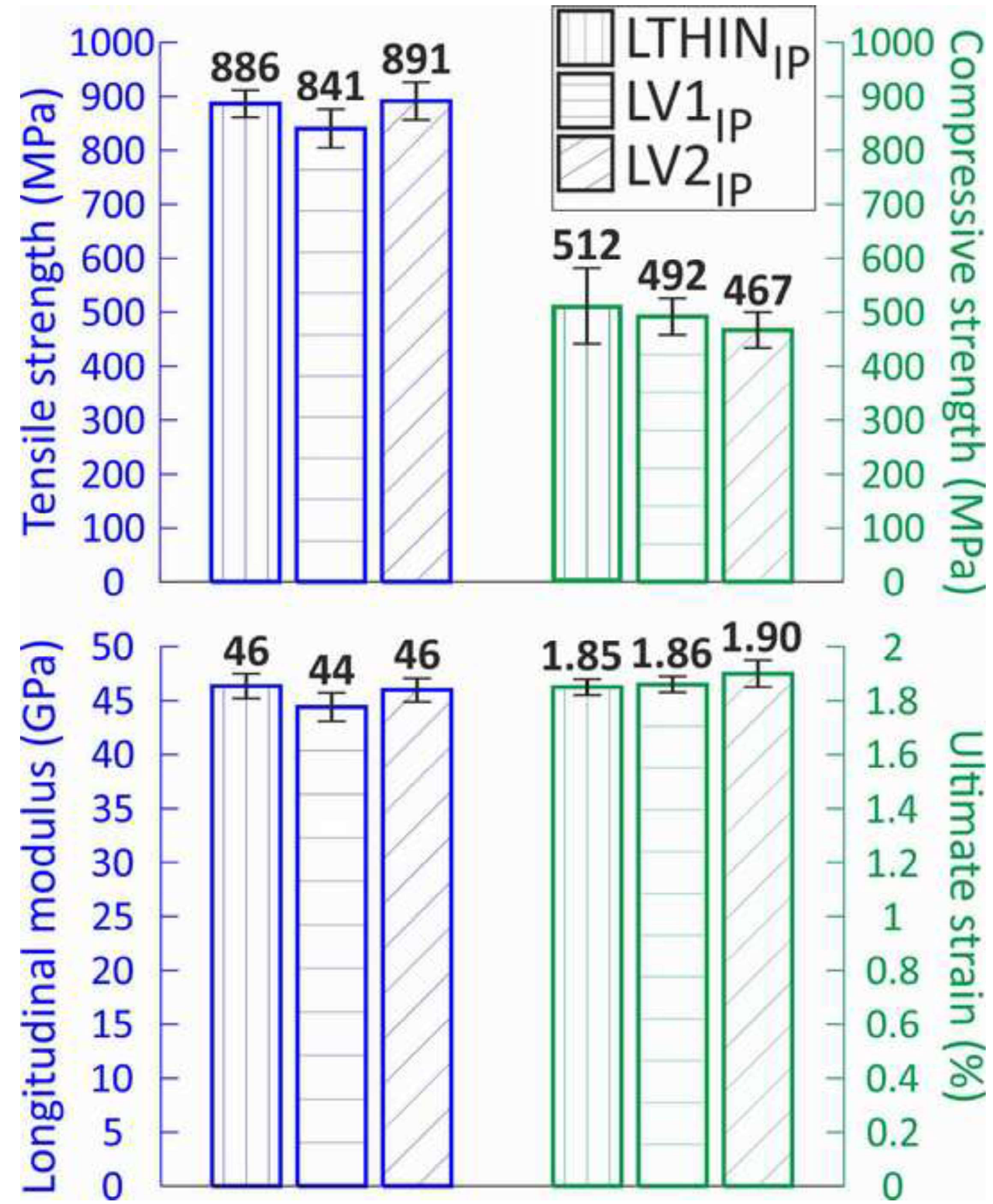

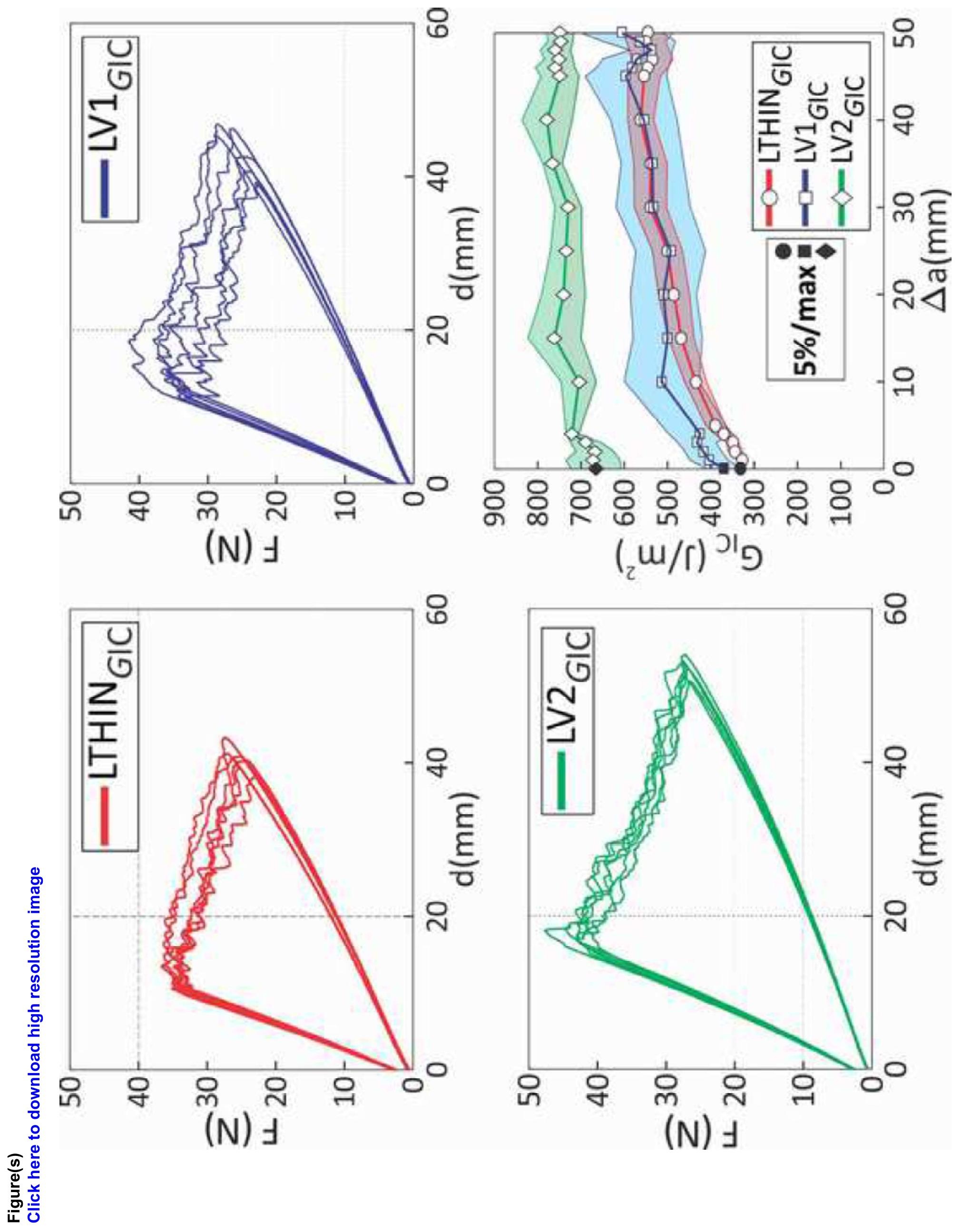


\section{$G_{\text {Iprop }}\left(\mathrm{J} / \mathrm{m}^{2}\right)$

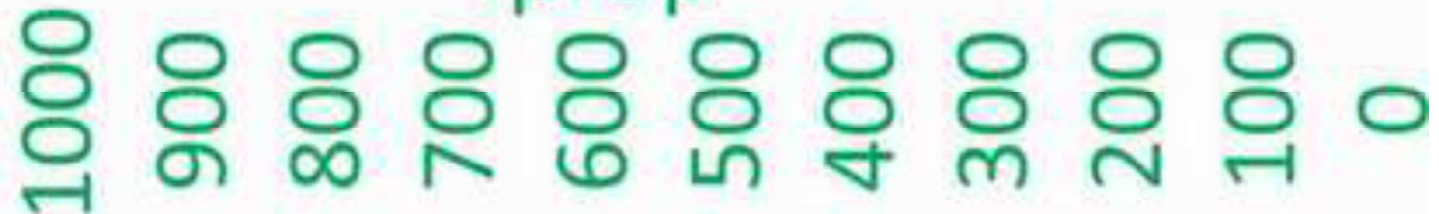

\begin{tabular}{|l|l|l|l|l|l|l|l|l|}
\hline & & & & & & & & \\
\hline
\end{tabular}

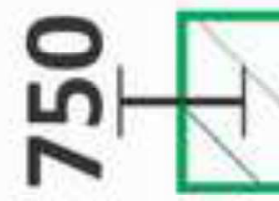

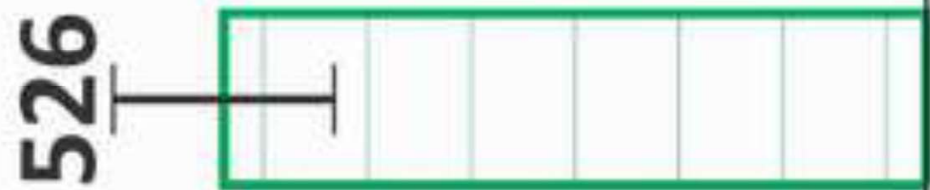

คิ

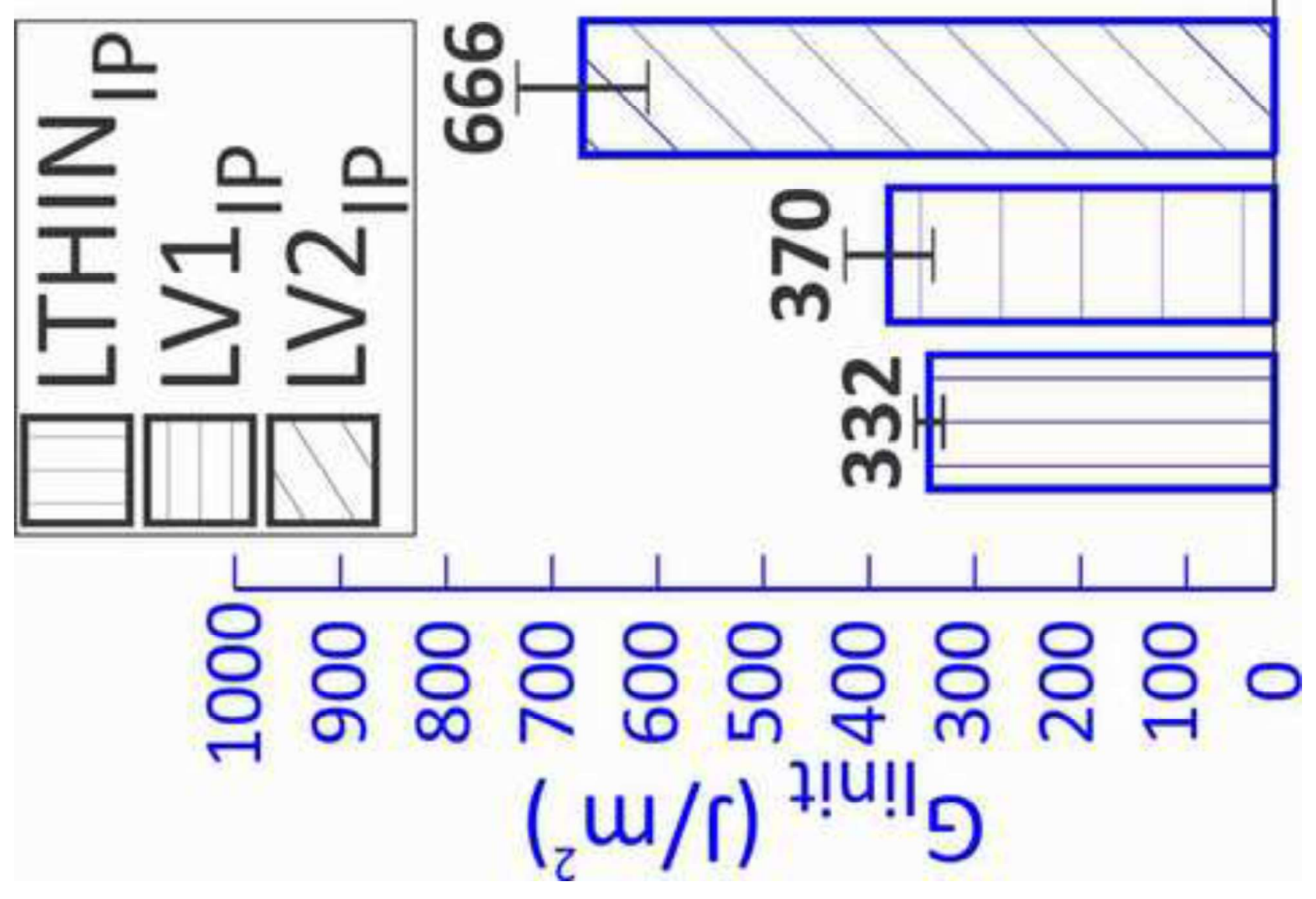




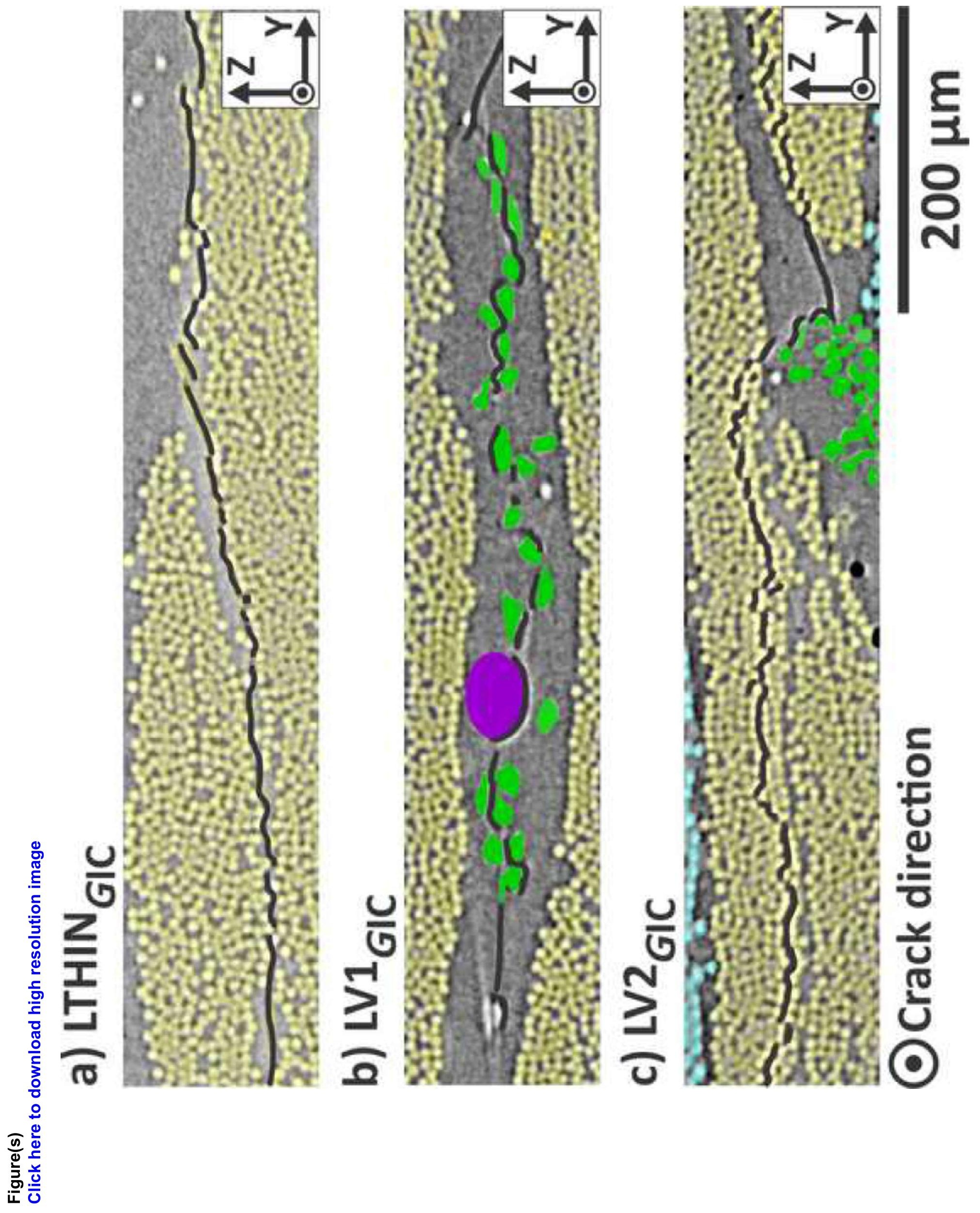




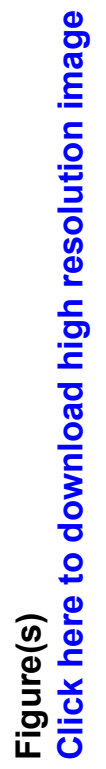
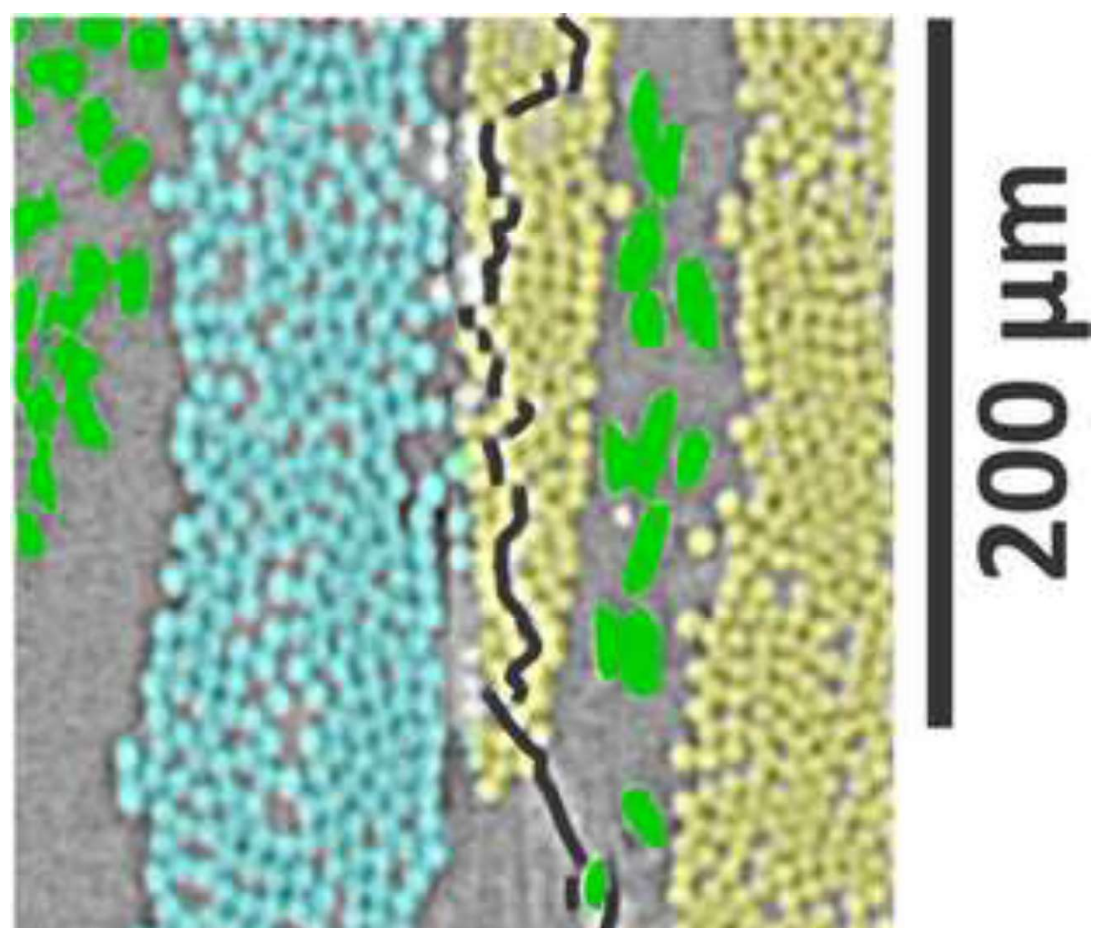

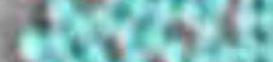

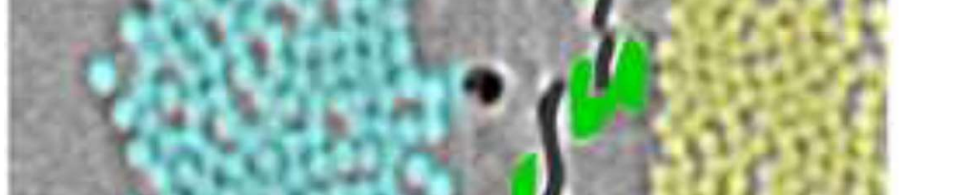

anding $=$

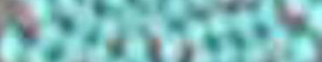
findinity $3, x^{2}+y^{2}+y^{2}$

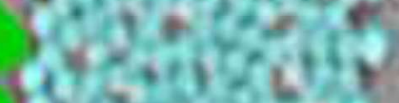
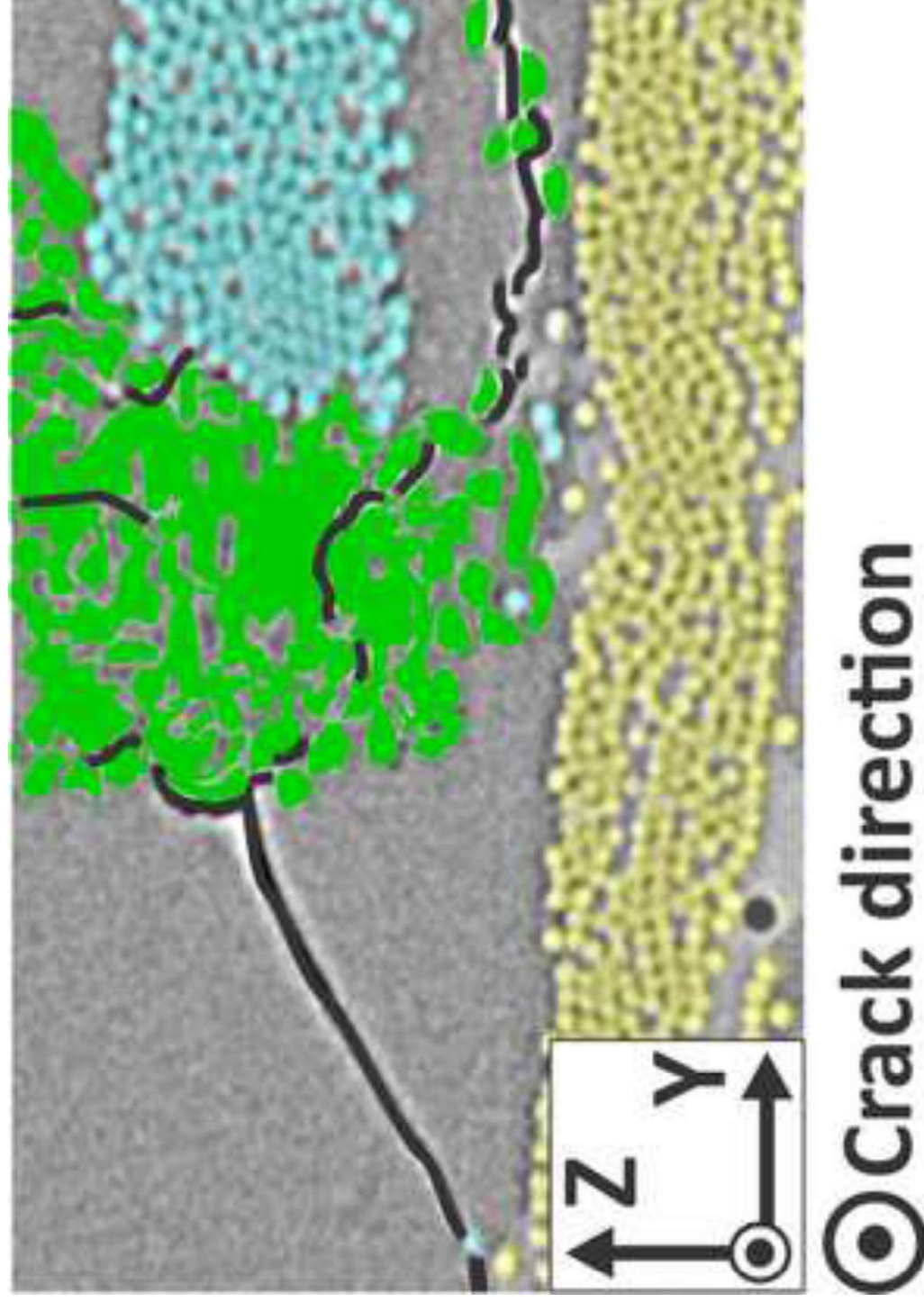


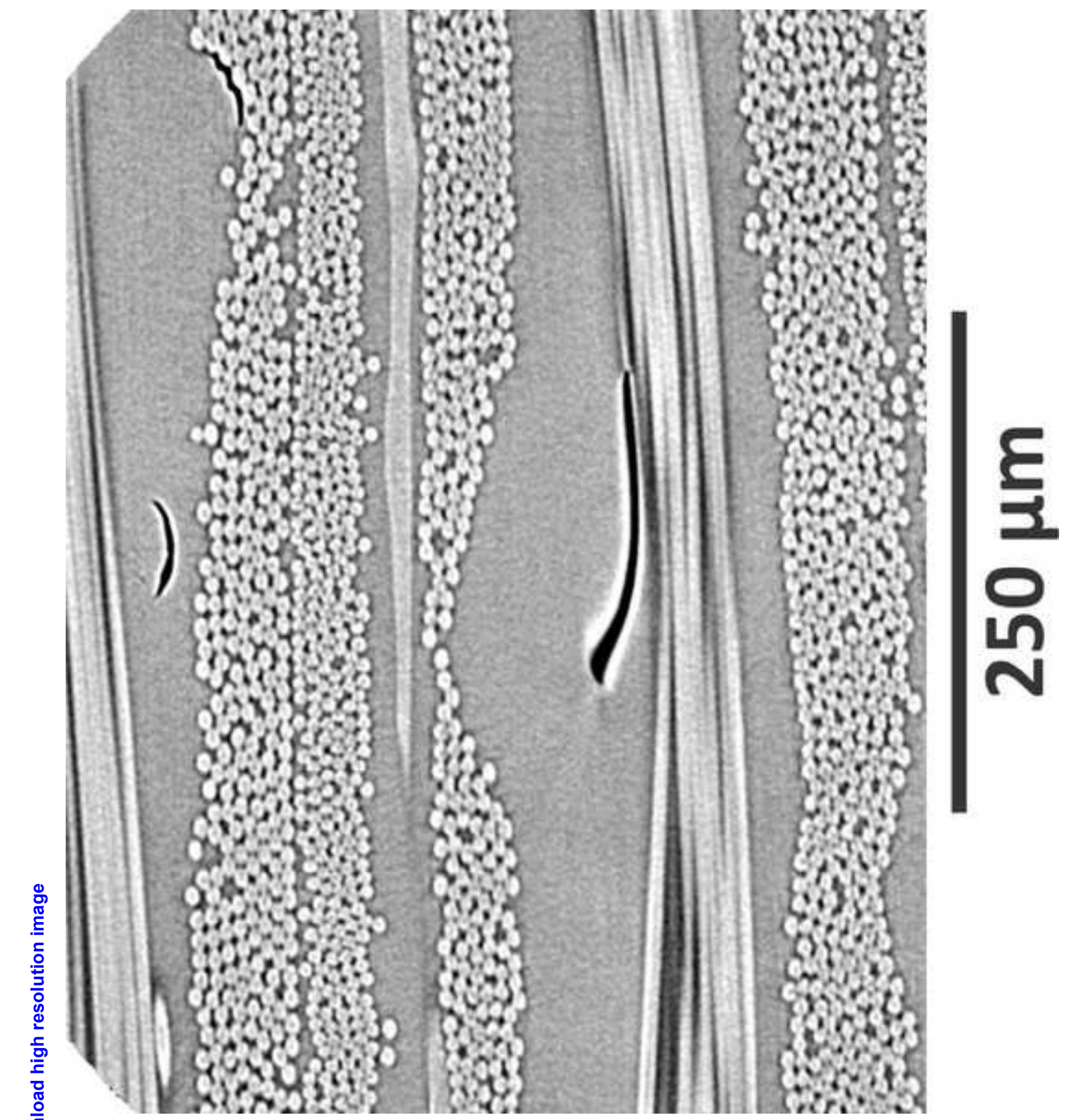




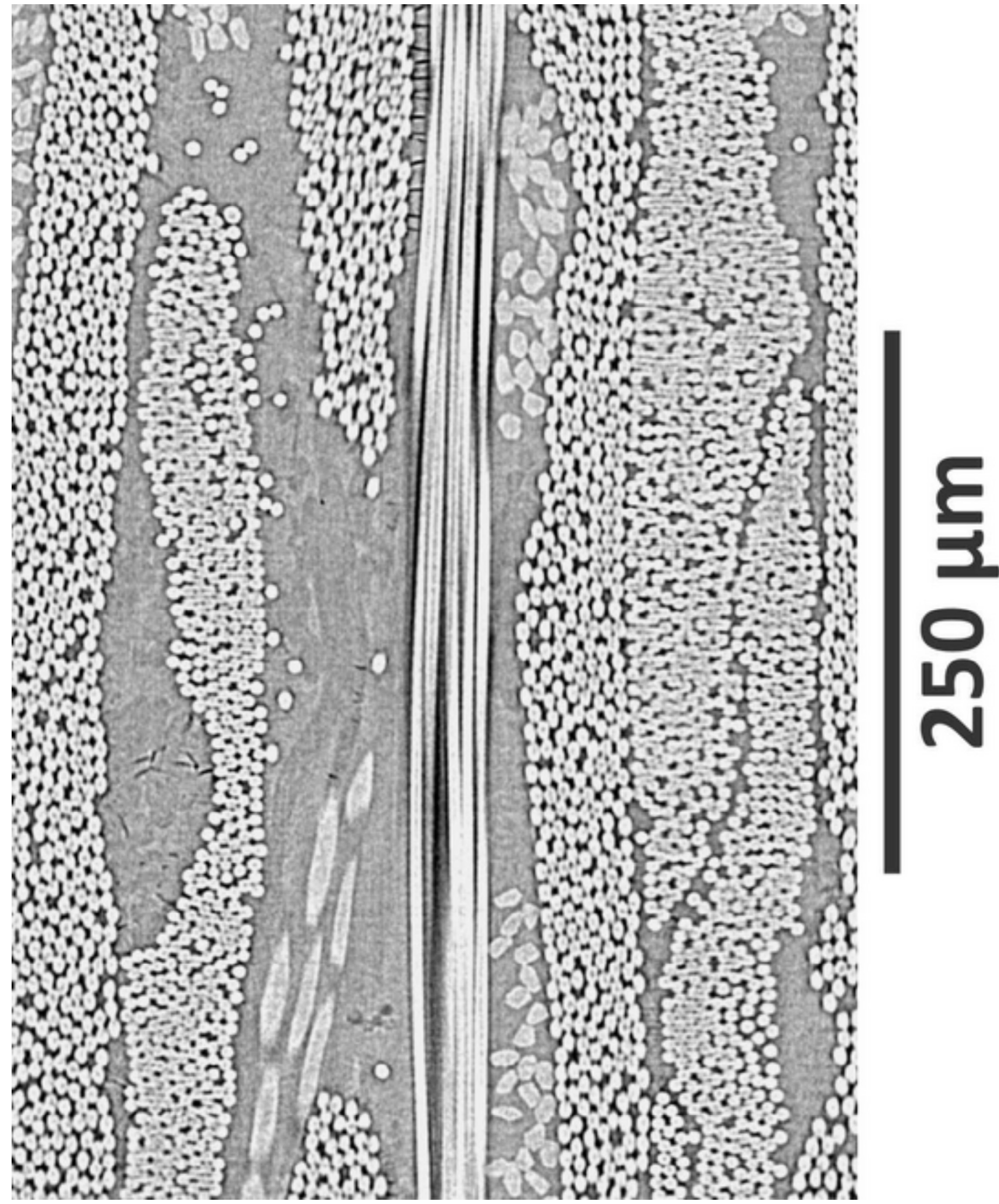




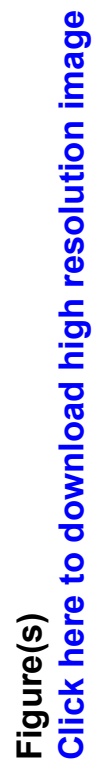

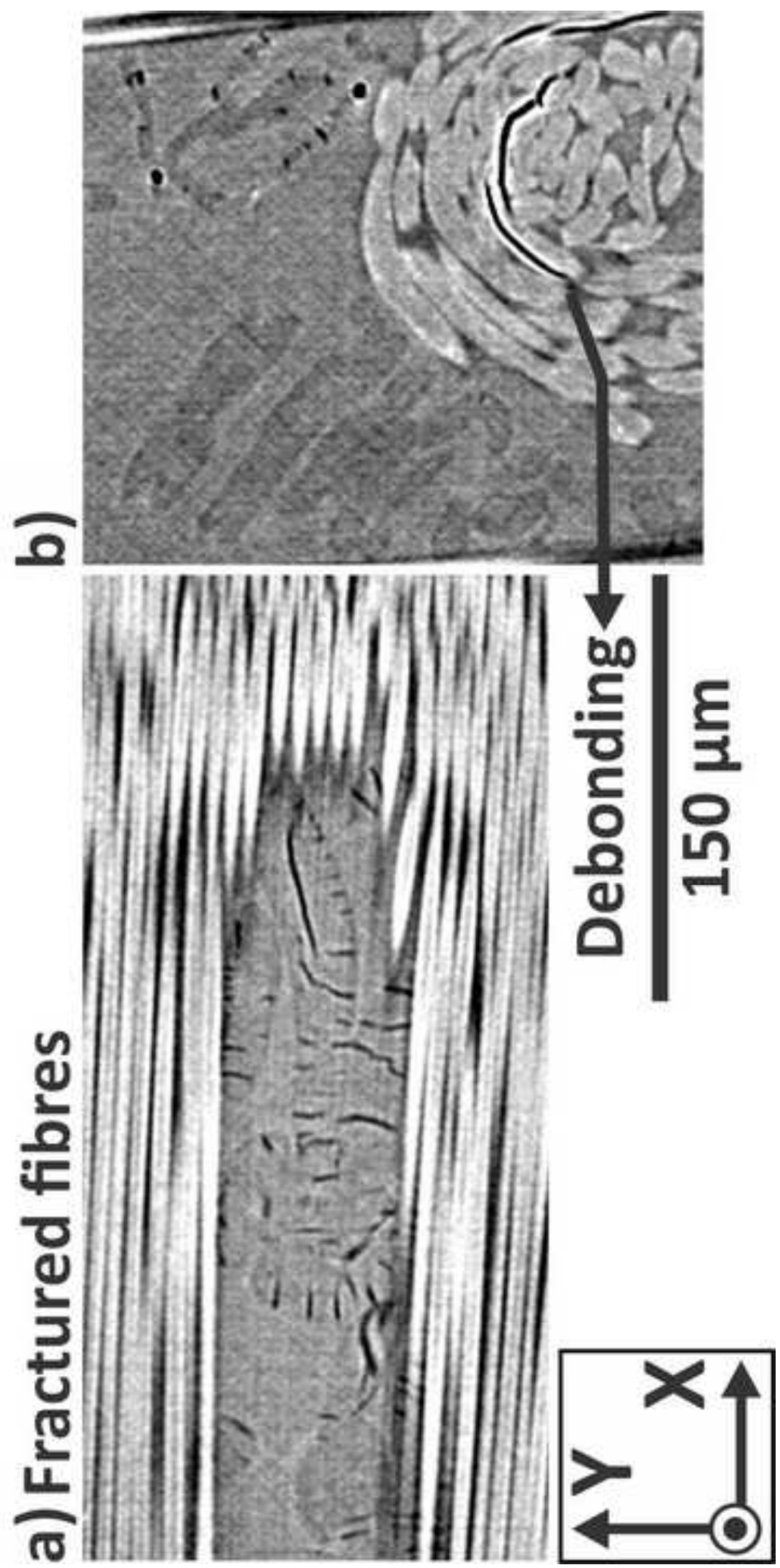




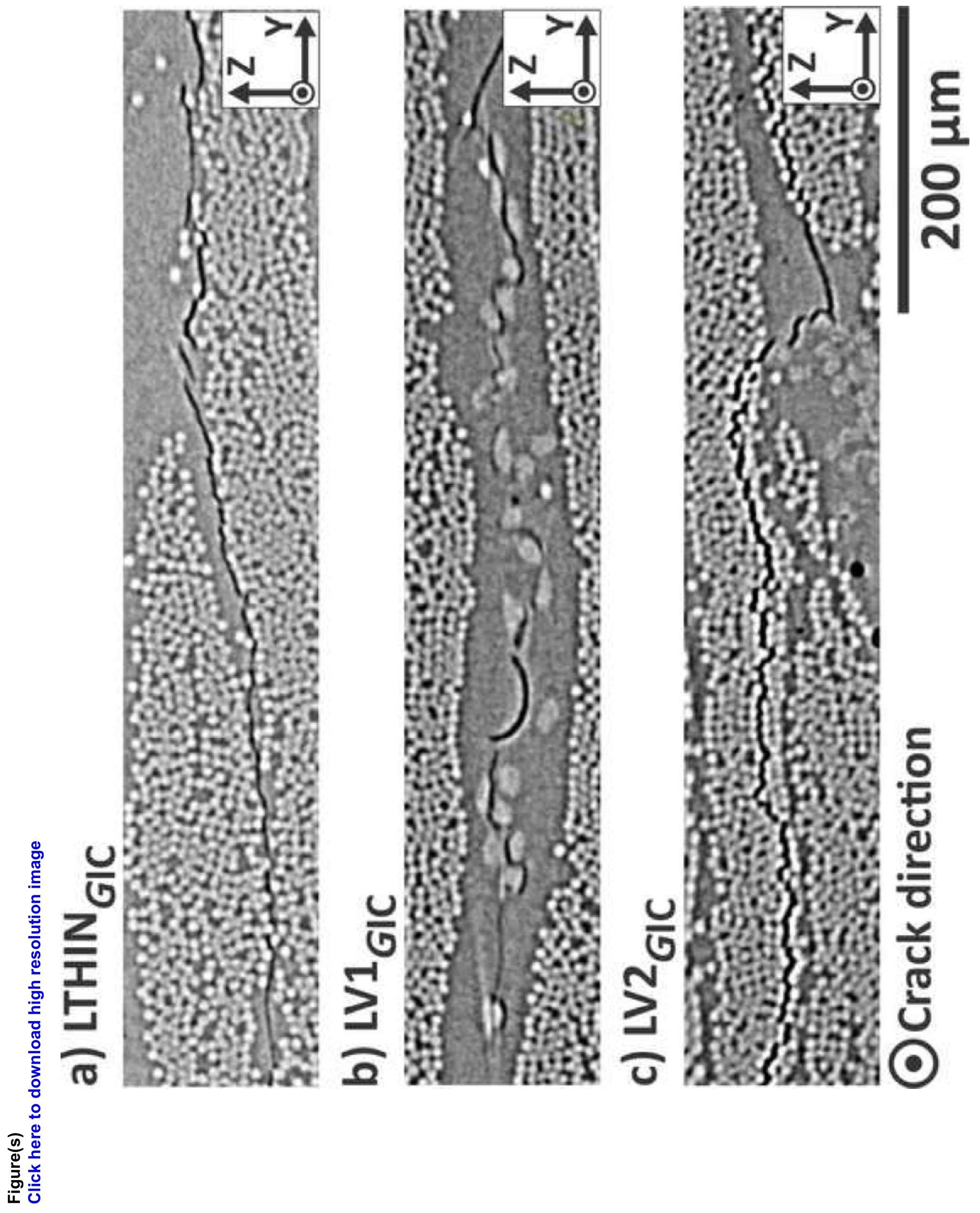




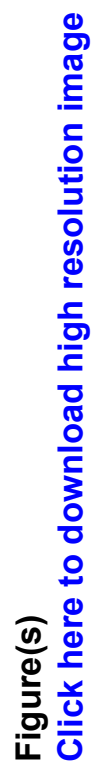
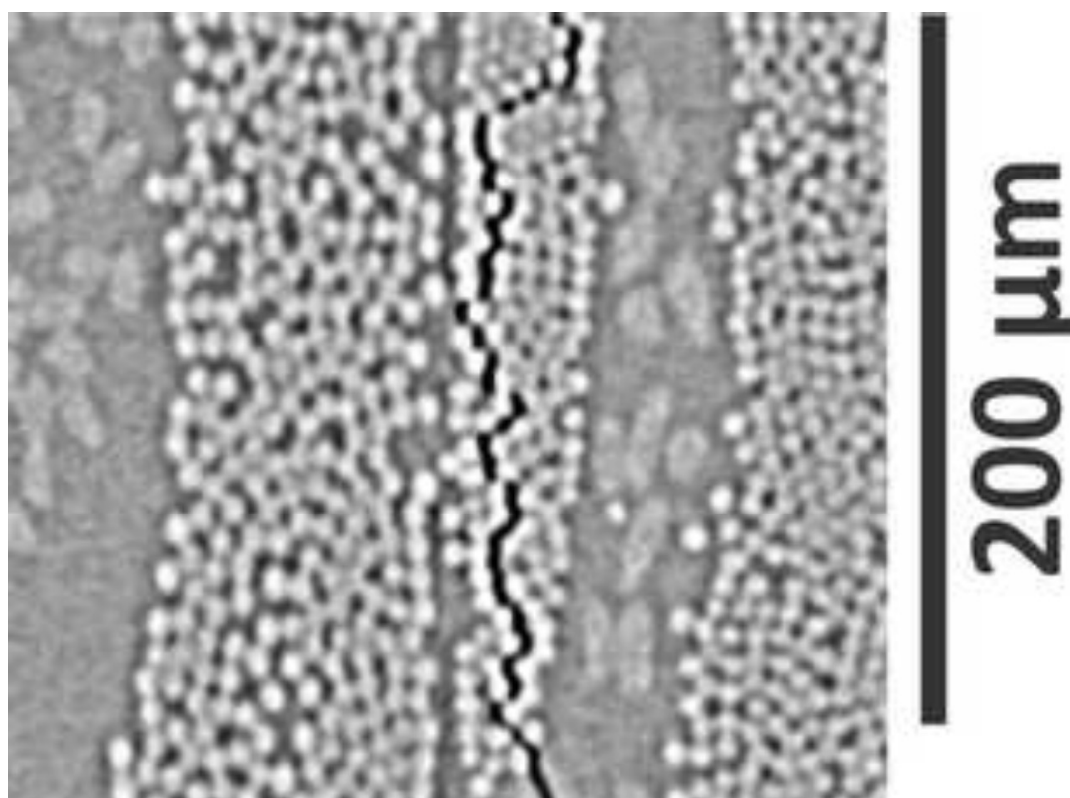

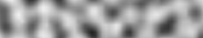

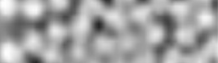

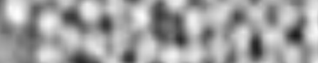

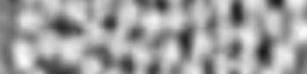

atistis:

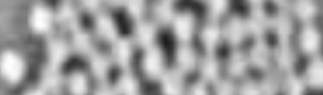

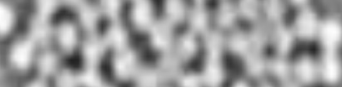

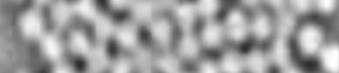

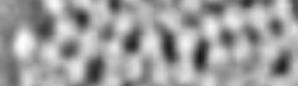

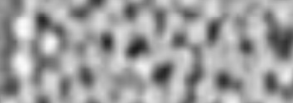

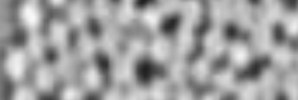

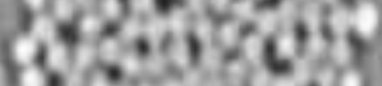
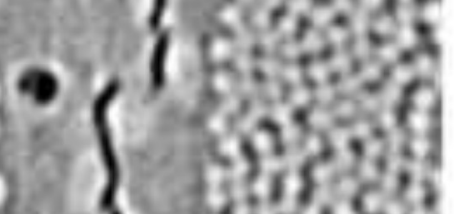

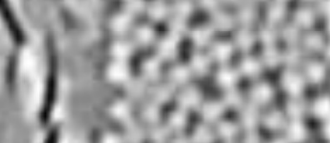

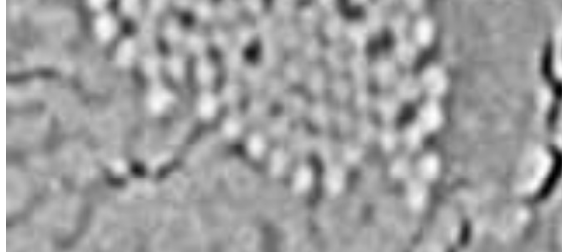

\section{en.}
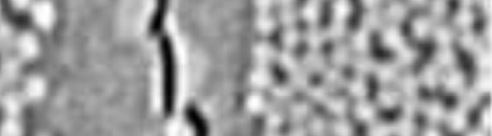
Click here to download LaTeX Source Files: Revised_manuscript.tex Click here to download LaTeX Source Files: Revised_manuscripttex

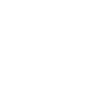


library
Click here to download LaTeX Source Files: library.bib

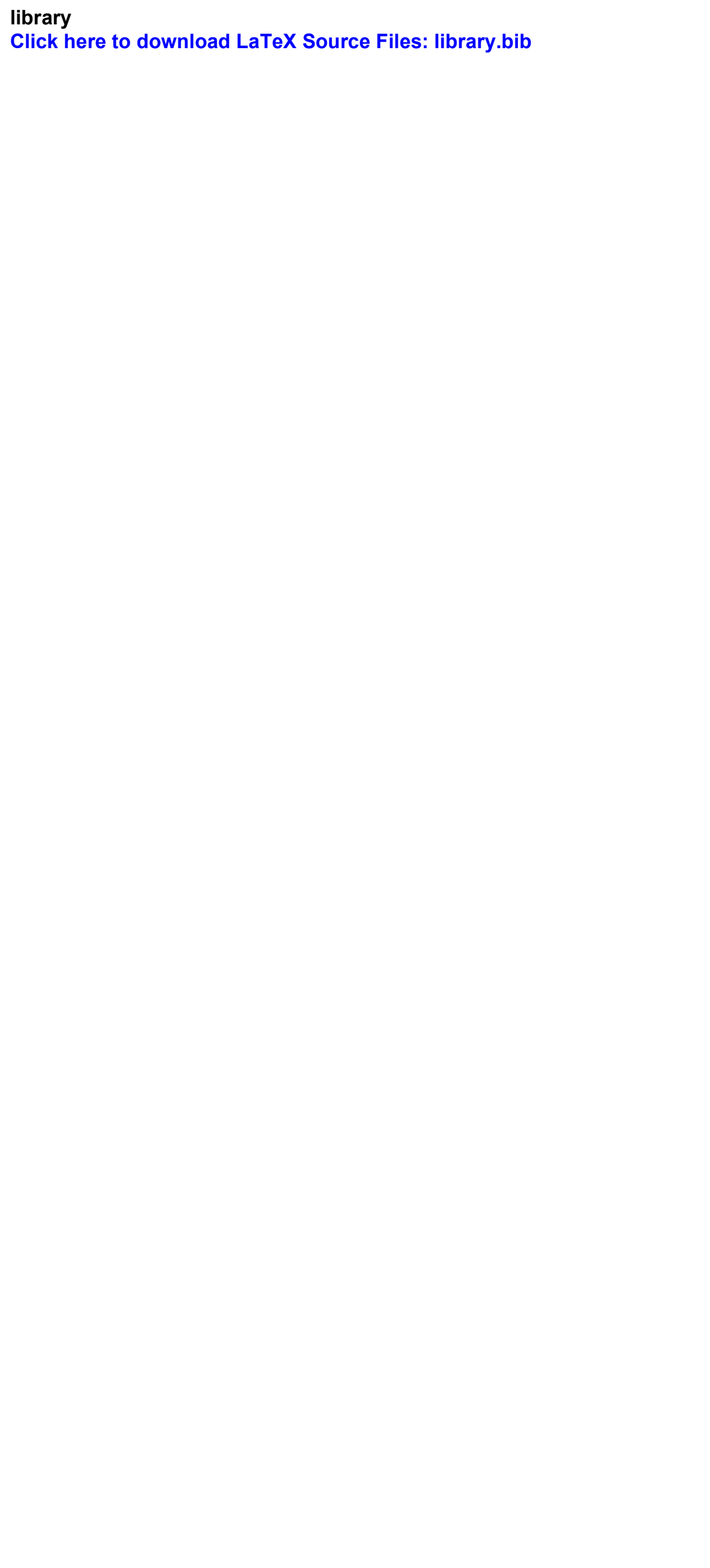

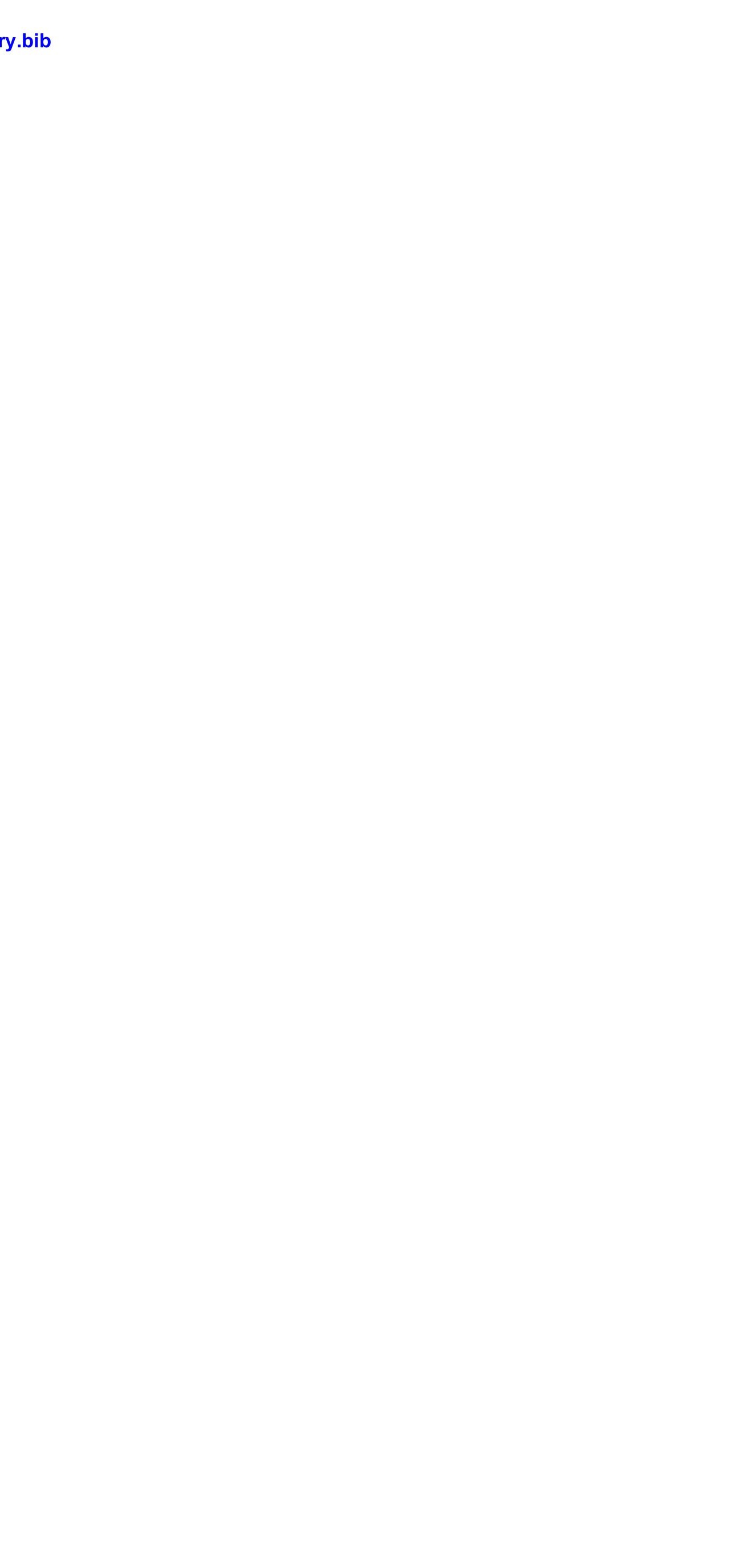


To whom it may concern,

We confirm that the manuscript is original and no part of it has been published before, nor is any part of it under consideration for publication at another journal. If accepted, it will not be published elsewhere in the same form, in English or in any other language, without the written consent of the publisher. There are no conflicts of interest to disclose. All authors have approved the manuscript and agree with the submission.

- All authors have participated in (a) conception and design, or analysis and interpretation of the data; (b) drafting the article or revising it critically for important intellectual content; and (c) approval of the final version.

- This manuscript has not been submitted to, nor is under review at, another journal or other publishing venue.

- The authors have no affiliation with any organization with a direct or indirect financial interest in the subject matter discussed in the manuscript.

Santiago García Rodríguez (University of Girona)

Josep Costa Balanzat (University of Girona)

Kathryn Rankin (University of Southampton)

Richard Boardman (University of Southampton)

Vicky Singery (Chomarat)

Joan Andreu Mayugo Majó (University of Girona)

30-July-2019 